\title{
金鸡纳生物碱及其衍生物在不对称催化中的研究进展
}

\author{
许双花 ${ }^{\dagger}$ 陈俊 ${ }^{\dagger}$ 陈加荣* 肖文精* \\ (华中师范大学化学学院 武汉 430079)
}

\begin{abstract}
摘要 金鸡纳生物碱广泛存在于自然界中，具有很好的生物活性和药用价值，且具有优势的手性骨架，易于修饰，引 起了化学家们广泛的研究兴趣. 随着不对称合成化学的发展, 化学家们将金鸡纳生物碱及其衍生物作为优势手性催化 剂或配体应用于许多不对称催化反应中. 尤其是近年来, 有机化学家们利用金鸡纳生物碱衍生的手性配体发展了一系 列金属催化不对称反应. 本综述较为详细地概述了近年来金鸡纳生物碱及其衍生物作为催化剂或配体参与的不对称催 化反应，探讨了相关反应机理，并对该研究领域未来发展前景进行了展望.
\end{abstract}

关键词 金鸡纳碱; 有机催化剂; 手性配体; 不对称合成; 不对称催化

\section{Recent Progress in Applications of Cinchona Alkaloids and Their Derivatives in Asymmetric Catalysis}

\author{
$\mathrm{Xu}$, Shuanghua ${ }^{\dagger} \quad$ Chen, Jun ${ }^{\dagger} \quad$ Chen, Jiarong* $\quad$ Xiao, Wenjing* \\ (College of Chemistry, Central China Normal University, Wuhan 43007)
}

\begin{abstract}
Cinchona alkaloids widely exist in nature, which have attracted extensive interest of researchers because of their readily availability, biological activity, unique structural properties, and easy modification. With the development of asymmetric synthetic chemistry, cinchona alkaloids and their derivatives have been used as a privileged class of chiral catalysts or ligands in many catalytic asymmetric reactions. In particular, a variety of cinchona alkaloid-derived chiral catalysts and ligands have been developed and applied by organic chemists in catalytic asymmetric synthesis in rencent years. The recent progress made in this field over the past few years is summarized. Moreover, the related reaction mechanisms and future development prospects are also discussed.
\end{abstract}

Keywords cinchona alkaloids; organic catalysts; chiral ligands; asymmetric synthesis; asymmetric catalysis

自 1737 年 Condamine 发现从金鸡纳树中提取出的 生物碱奎宁可作为治疗㾏疾的特效药以后, 金鸡纳生物 碱就开始受到人们的普遍关注 ${ }^{[1]} .1820$ 年, Pelletier 和 Caventou 首先分离得到奎宁纯品 ${ }^{[2]}$, 随后 Rabe 等 ${ }^{[3]}$ 于 1907 年确定了奎宁的分子结构, 其全合成工作首次于 1944 年由 Woodward 和 Doering ${ }^{[4]}$ 报道. 1967 年, Carter 等 ${ }^{[5]}$ 通过单晶衍射进一步确定了奎宁的结构. 直到 2001 年, Stork 等 ${ }^{[6]}$ 利用手性的 Taniguchi 内酯作为初始原料历 经 15 步反应后才得到光学纯的奎宁. 研究者们陆续从 金鸡纳属中提取出约 30 种天然生物碱, 并广泛用于医 学、制药等领域. 由于金鸡纳生物碱具有含量丰富、稳 定性好以及优势的手性骨架, 金鸡纳生物碱及其衍生物
被作为有机催化剂和手性配体广泛用于催化不对称合 成, 已经成为不对称合成化学中的一个重要研究领域.

在有机小分子催化的不对称合成中, 自 1853 年 ${ }^{[7]}$ 金鸡纳生物碱首次被报道可作为手性助剂参与不对称 合成后, 金鸡纳生物碱作为有机催化剂或手性配体参与 不对称合成已成为热门研究内容之一. 这与其具有天然 的手性环境结构及强大的后期可修饰能力密不可分 (Scheme 1). 可归纳为以下几点: (1)奎宁、喹啉环可产生 具有类似酶的手性口袋提供手性环境; (2) $\mathrm{R} 、 \mathrm{OH}$ 和奎宁 环等都具有可修饰性; (3) C8 与 C9 的自由旋转创造动态 环境可产生不同稳定性的构像; (4)奎宁环中的叔胺氮原 子具有亲核特点, 可作为亲核试剂活化底物; (5)扁平的

\footnotetext{
* Corresponding authors. E-mail: chenjiarong@mail.ccnu.edu.cn; wxiao@mail.ccnu.edu.cn

Received July 1, 2020; revised August 1, 2020; published online August 11, 2020.

Dedicated to the 40th anniversary of Chinese Journal of Organic Chemistry.

Project supported by the National Natural Science Foundation of China (Nos. 21820102003, 91956201).

国家自然科学基金(Nos. 21820102003, 91956201)资助项目.

共同第一作者(These authors contributed equally to this work).
} 
喹啉芳香环富电子可与缺电子分子形成电子给体供体 复合物(EDA); (6) C9 位上的羟基可通过氢键作用作为 亲电试剂活化底物. 在过去几十年, 通过对金鸡纳生物 碱结构的修饰, 已经衍生出诸多具有代表性的金鸡纳碱 衍生物, 如 C9-胺基、脲/硫脲、酰胺、磺酰胺、方酰胺、 醚等; C6' $^{\prime}$-羟基以及二聚或多聚高分子化合物(Scheme 2). 关于这些衍生物的具体合成, Skarżewski 等 ${ }^{[8]}$ 在其 2019 年的综述中已做了非常详细地总结. 本文将按照 金鸡纳碱及其衍生物在不对称合成中的角色进行分类, 对其作为催化剂和配体参与的不对称反应进行归纳和 总结，并探讨了相关反应机理.

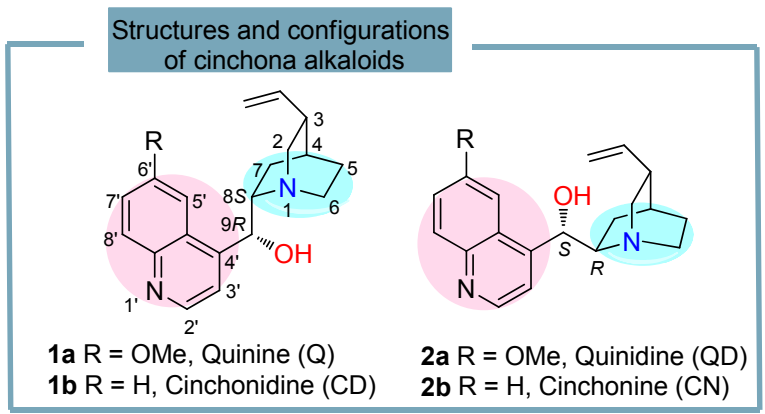

图式 1 金鸡纳生物碱的结构与构型

Scheme 1 Structures and configurations of cinchona alkaloids

\section{2 金鸡纳碱及其衍生物作为有机催化剂}

在不对称催化领域中, 有机小分子催化相较于金属 催化和酶催化更具绿色经济以及可持续性, 一直以来都 受到人们的广泛关注. 有机催化的起源最早可以追溯到 二十世纪初 Knoevenagel 等化学家报道的有机胺催化反 应 $^{[9]}$. 随后, 有机小分子催化的不对称合成研究序幕慢 慢被拉开, 有机胺、磷、嗍试剂、脯氨酸、金鸡纳碱和 杂环卡宾等以及各自的衍生物被发现可催化多类有机 化学反应, 从而有效构建碳一碳键或碳-杂键. 对于催化 模式, 则主要包括烯胺催化、亚胺催化、SOMO (singly occupied molecular orbital)催化、氢键活化、卡宾催化以 及相转移催化等 ${ }^{[10]}$, 而金鸡纳碱及其衍生物作为有机 小分子催化中的重要分支, 尤其是自 2000 年以来已取 得突飞猛进的发展. 邓力教授作为该领域的开拓者和引 领者之一, 在金鸡纳碱催化领域取得了重要突破, 也因 此荣获了 2020 年 “亚瑟・科普学者奖”。许多具有代表 性的综述 ${ }^{[11]}$ 在此之前已经详尽地总结了相关工作, 故本 部分将对 2016 年以来发展的金鸡纳碱及其衍生物催化 的不对称合成研究进行总结.

\subsection{C-9 衍生的金鸡纳碱衍生物}

作为一种原子经济性的合成策略, 催化不对称 Diels-Alder 反应被广泛应用于构建结构多样的手性六

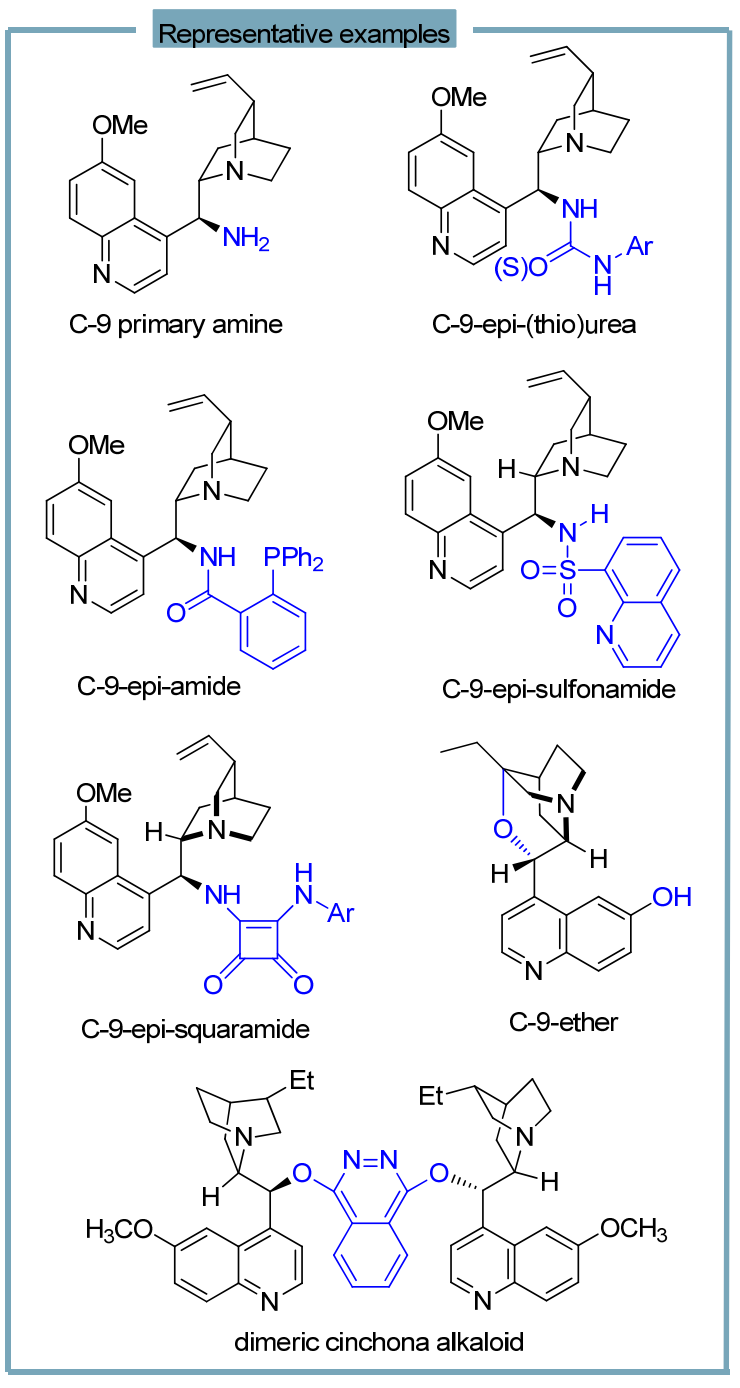

图式 2 金鸡纳碱衍生物催化剂的代表性例子 Scheme 2 Representative examples of cinchona alkaloid-derived catalysts

元碳环或杂环化合物. 2017 年, 王春江课题组 ${ }^{[12]}$ 报道了 在金鸡纳碱衍生的双功能胺-硫脲催化剂 1 的催化作用 下，通过去对称化策略实现了 3-着基-2-吡喃酮 3 与潜手 性的 1,3-二酮 4 的不对称 Diels-Alder 反应，从而构建了 一系列具有五个手性中心的桥环内酯化合物 5 (Scheme 3). 在该反应中, 由于底物 3-羟基-2-吡喃酮固有的缺电 子性质, 以及环加成产物中四个连续手性中心和一个远 端季碳中心的一次性构建，使得该反应具有一定的挑战 性. 作者利用双功能胺一硫脲催化剂解决了这一难题, 且能以良好的收率、对映选择性以及非对映选择性得到 外型产物. 作者认为硫嫝单元、羟基结合的多氢键供体 与三级胺双活化模式是该反应能顺利进行的关键. 利用 这种合成策略可以方便地构建环状化合物，这类结构在 天然产物的全合成中有一定的应用潜力.

手性含氮杂环化合物广泛存在于许多天然产物和 


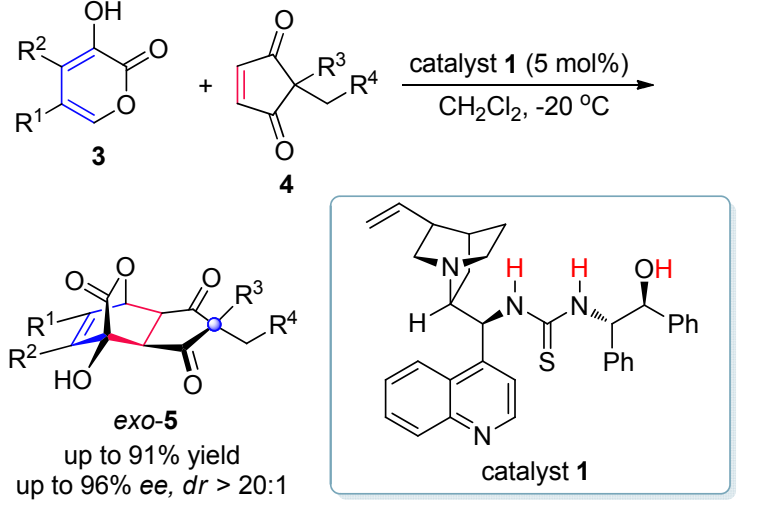

$\mathrm{R}^{1}=\mathrm{H}, \mathrm{Et} ; \mathrm{R}^{2}=\mathrm{H}, \mathrm{Cl}, \mathrm{Me}, \mathrm{Et} ; \mathrm{R}^{3}=\mathrm{Me}, \mathrm{Et} ; \mathrm{R}^{4}=$ alkyl, aryl, alkenyl

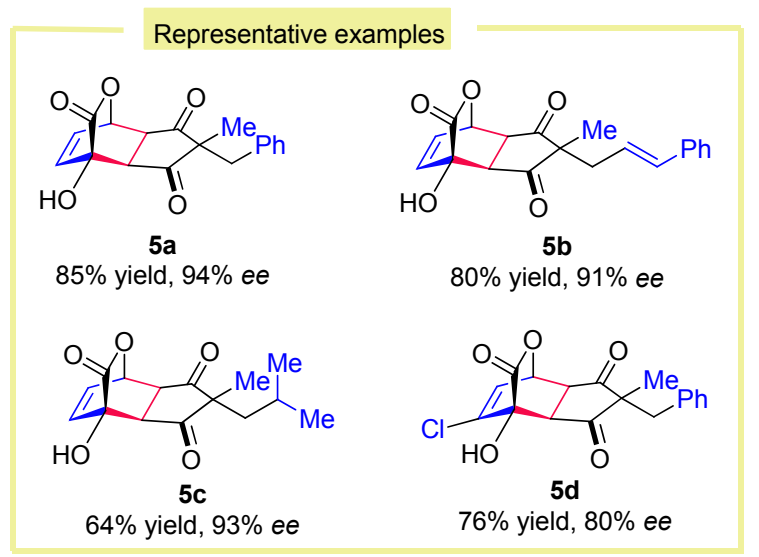

图式 3 金鸡纳碱衍生的胺-硫嫝催化的不对称 Diels-Alder 反 应

Scheme 3 Asymmetric Diels-Alder reaction catalyzed by cinchona alkaloid-derived amine-thiourea

生物活性分子中, 也可以作为手性配体或催化剂被广泛 应用于不对称合成反应中. 因此, 手性含氮杂环化合物 的合成一直受到科研工作者的密切关注. 2019 年, 程道 娟课题组 ${ }^{[13]}$ 利用金鸡纳碱衍生的胺一硫脲双功能催化剂 2, 以 $3 H$-吲哚 6 和硝基取代的烷烃 7 作为底物, 在温和 的条件下实现了不对称 Aza-Henry 反应, 以中等到良好 的收率和对映选择性成功地实现了非活化的五元环亚 胺到手性含氮杂环 8 的转换(Scheme 4). 在此反应中, 当 $\mathrm{R}^{2}$ 是甲基时, 可能形成了环状三聚体, 反应不能够发 生. 但是当 $\mathrm{R}^{2}$ 是正丁基时，通过延长反应时间，能够以 $51 \%$ 的收率和 $80 \%$ 的对映选择性得到目标产物. 另一方 面, 当选用 1-硝基丙烷作为亲核试剂时, 该反应的效率 和立体选择性明显降低, 可能是因为吲哚 3-位的大基团 阻碍了空间位阻较大的亲核试剂的进攻. 作者认为, 催 化剂 2 中奎宁环部分首先脱去底物 7 中的质子, 生成真 正的亲核硝酸盐物种, 其自身被质子化. 随后质子化的 催化剂 2 通过氢键作用同时活化 $3 H$-吲哚 $\mathbf{6}$ 和真正的亲 核物种硝酸盐, 这样, Aza-Henry 加成选择性在底物 $3 H$ 吲哚 6 的 $S i$ 面进行, 从而生成 $R$ 构型的产物.

同年, Pan 课题组 ${ }^{[14]}$ 利用同样的催化剂 2 实现了二

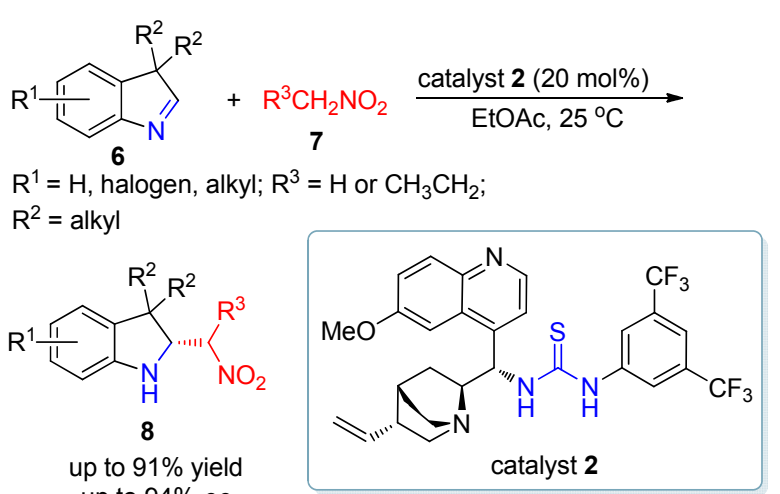
up to $94 \%$ ee

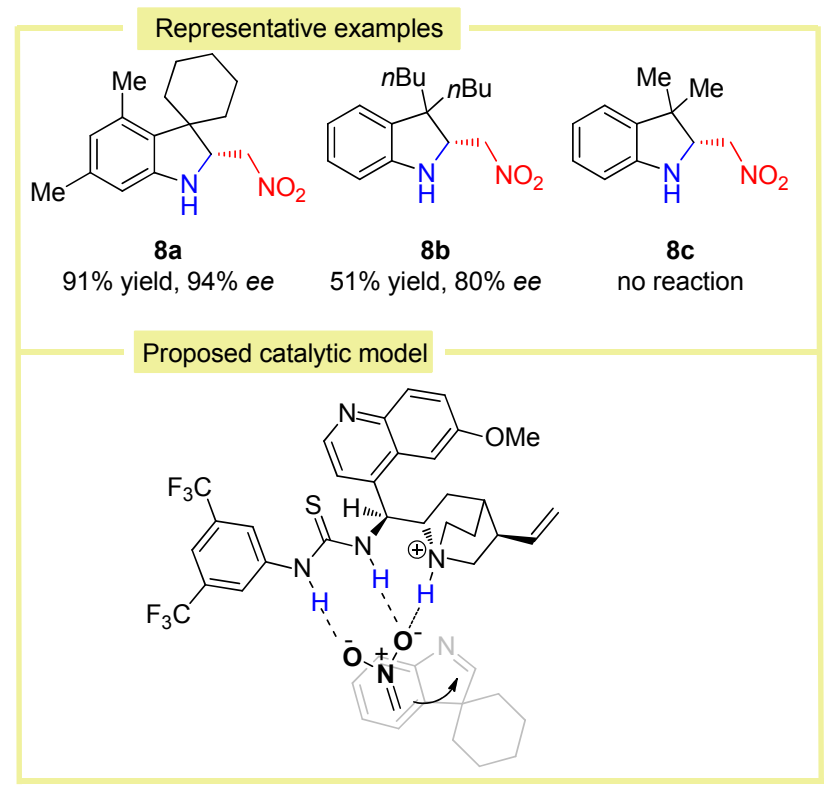

图式 4 金鸡纳碱衍生的胺-硫嫝催化的不对称 Aza-Henry 反 应

Scheme 4 Asymmetric aza-Henry reaction catalyzed by aminethiourea from cinchona alkaloid

氢-3-烷氧羰基-2-喹诺酮 9 与 Boc 保护的亚胺 10 的不对 称 Mannich 反应(Scheme 5). 在该反应中, 反应条件温 和, 操作简单, 具有较好的官能团兼容性, 最终能以中 等到良好的收率和对映选择性, 以及中等的非对映选择 性合成得到具有重要潜在生物活性的 3,3-二取代-二氢2-喹诺酮类化合物 11. 对于金鸡纳碱衍生的胺一硫䣝催 化剂的双活化模式, 作者认为, 催化剂 2 奎宁环片段中 的三级胺作为布朗斯特碱活化底物 9 中烯醇互变所产生 的羟基，而硫䐂单元作为氢键供体活化底物亚胺，从而 选择性地在亚胺的 $S i$ 面发生亲核加成生成 $(S, S)$ 构型的 产物 11.

在金鸡纳碱衍生的双功能催化剂中，除 C9 位含有 硫脲单元外, C9 位含有磺酰胺和四方酰胺结构单元也是 十分优良的氢键供体. 2018 年, Funahashi 课题组 ${ }^{[15]}$ 利用 金鸡纳碱衍生的磺酰胺催化剂 $\mathbf{3}$, 实现了 $2 H$-氮杂丙烯 啶与硫醇 13 的不对称亲核加成反应，以高收率和高对 


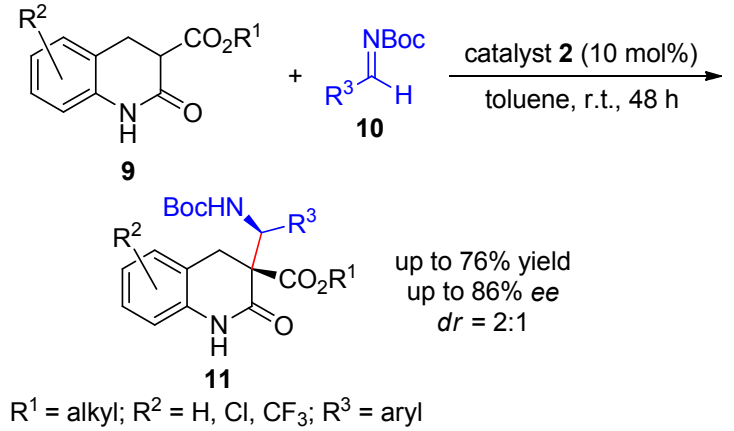

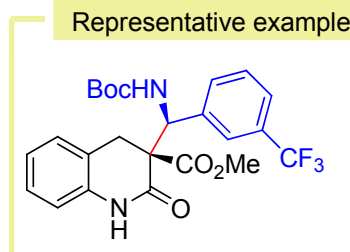

$11 \mathrm{a}, 76 \%$ yield $86 \%$ ee, $d r=2: 1$

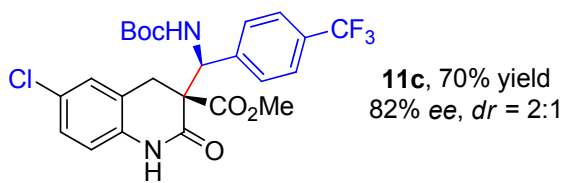
Proposed catalytic model

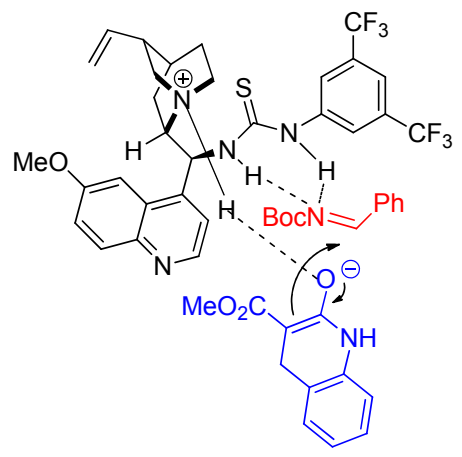

图式 5 金鸡纳碱衍生的胺-硫脲催化的不对称 Mannich 反应 Scheme 5 Asymmetric Mannich reaction catalyzed by cinchona alkaloid-derived amine-thiourea

映选择性制备了一系列氮杂环丙烷类化合物 14, 并且 该产物在不损失对映选择性的条件下可以转化为噁唑 啉或 $\alpha$-磺酰酯等具有季碳中心的手性化合物 (Scheme 6). 在该反应中, 初始原料叠氮丙烯酸酯 12 在溶剂二氯 甲烷中封管加热即可原位生成 $2 H$-氮杂丙烯啶. 随后在 催化剂 3 的催化下, 硫醇作为亲核试剂对其进行亲核加 成. 作者认为该反应优异的收率和对映选择性正是得益 于金鸡纳碱衍生的磺酰胺催化剂的双功能活化. 另外, 催化剂 3 中的杂芳烃磺酰基在增强反应的对映选择性中 起重要作用.

2016 年, Itsuno 课题组 ${ }^{[16]}$ 合成了一类以金鸡纳碱衍 生的磺酰胺为重复单元的手性聚合物, 并成功应用到环 酤的不对称去对称化反应中(Scheme 7). 以四氢呋喃作
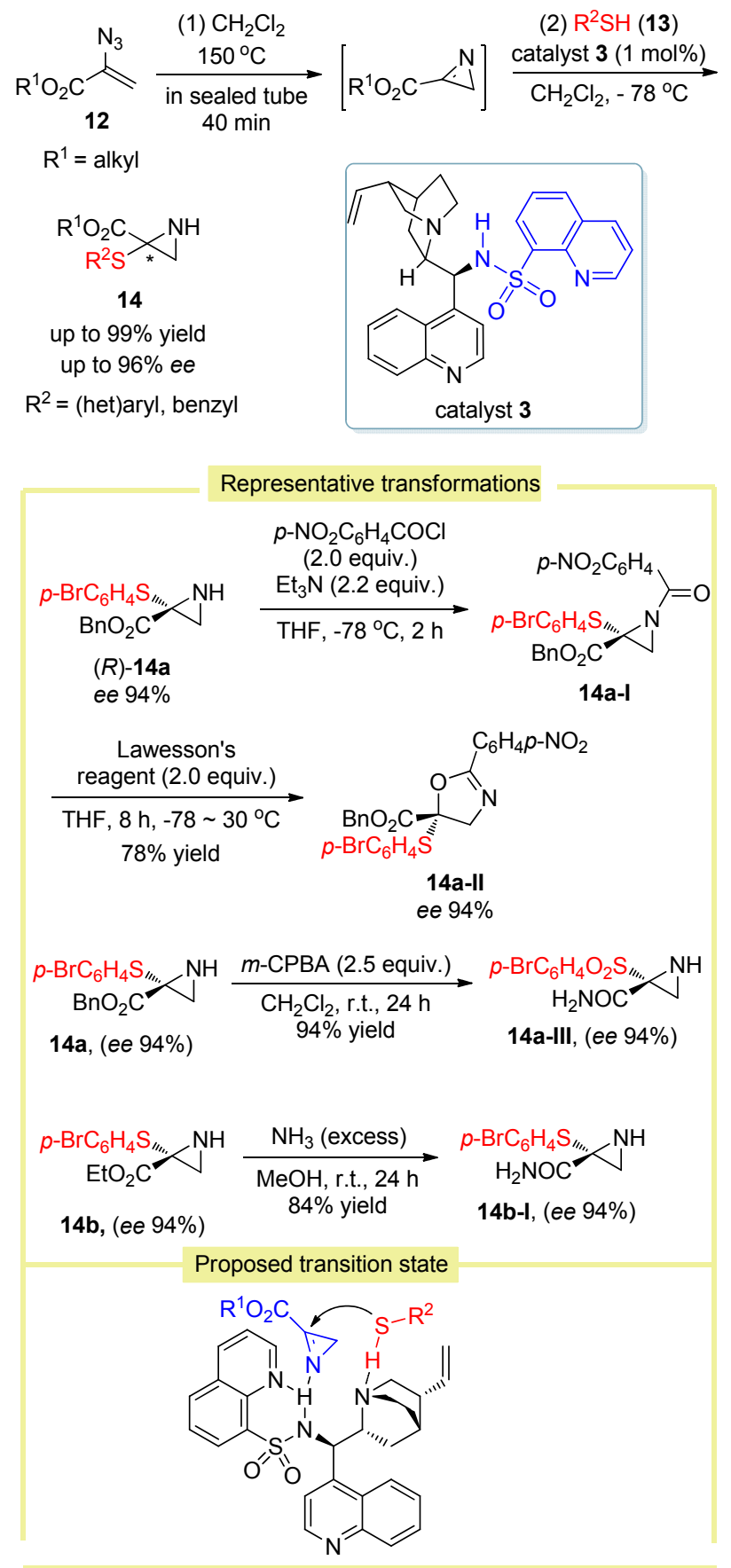

图式 6 金鸡纳碱衍生的磺酰胺催化的不对称亲核加成 Scheme 6 Asymmetric nucleophilic addition catalyzed by cinchona alkaloid-derived sulfonamide

溶剂，底物环酐 $15 \mathrm{a}$ 与甲醇、茮醇、烯丙醇 $16 \mathrm{a}$ 均能以 中等到良好的收率和对映选择性得到去对称化的产物 17a. 随后，该团队又合成了基于辛可尼啶的磺酰胺二 聚体为重复单元的手性聚合物 ${ }^{[17]}$, 并成功地应用于 $\beta$-酮 酯 $15 b$ 和硝基苯乙烯 $16 \mathrm{~b}$ 的不对称 Michael 加成反应中. 尽管此类手性聚合物不溶于常用的有机溶剂，但在非均 相反应条件下所表现出的催化活性和金鸡纳生物碱衍 生的磺酰胺类催化剂在均相条件下所表现出的活性相 
当. 并且, 聚合物催化剂 4 可以通过简单过滤从反应混 合物中分离出来. 将回收的聚合物粉末重新用于后续反 应，不会造成催化活性和产物的对映选择性损失.

(a)

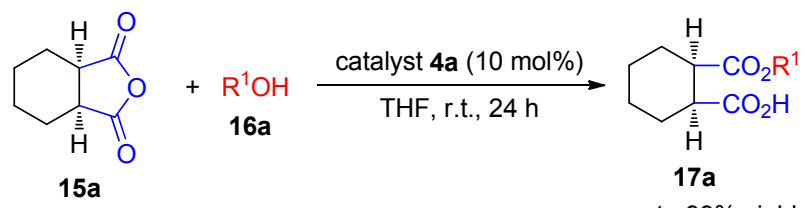
$\mathrm{R}^{1}=\mathrm{CH}_{3}$, benzyl, allyl

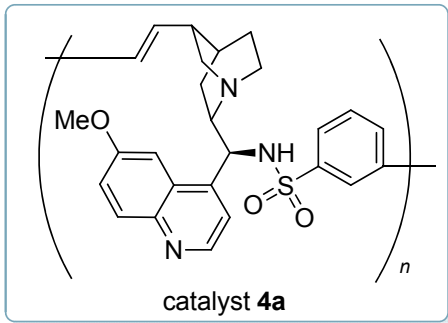

(b)<smiles>[R]OC1CCCC1=O</smiles>

$15 b$ $\mathrm{R}^{2}=\mathrm{Me}, \mathrm{Et}$

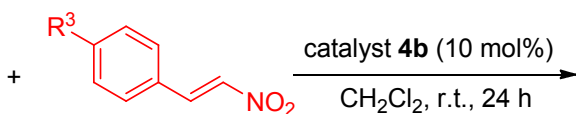

$16 \mathrm{~b}$
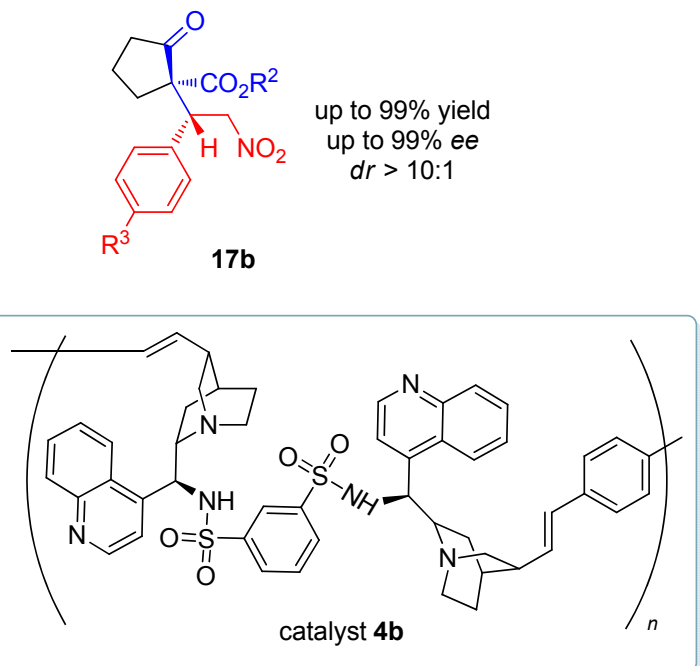

图式 7 金鸡纳碱衍生的多聚磺酰胺催化的不对称亲核加成 反应

Scheme 7 Asymmetric nucleophilic addition catalyzed by cinchona alkaloid-derived sulfonamide polymers

多取代的四氢呋喃或吡喃广泛存在于天然产物和 药物中. 然而, 由于存在较大的空间位阻, 此类化合物 的对映选择性合成仍具有很大的挑战性. 2016 年, Ghorai 课题组 ${ }^{[18]}$ 报道了在金鸡纳碱衍生的四方酰胺催 化剂 5 的作用下, 实现了对位取代的苯酚 18 氧化脱芳构 化/不对称的 Oxa-Michael 加成串联反应(Scheme 8). 在 $\mathrm{PhI}(\mathrm{OAc})_{2}$ 为氧化剂的条件下, 底物 18 脱芳构化得到 4-
羟基环已二烯酮 19. 随后在催化剂 5 的作用下, 19 发生 对映选择性的分子内 Oxa-Michael 加成反应. 利用这种 两步一锅的策略能够高效地合成一系列四氢呋喃和四 氢吡喃类化合物 20 . 该反应具有出色的对映选择性, 底 物普适性较好，适用于 $\alpha, \beta$-不饱和的芳香酮、杂环酮以 及脂肪酮。

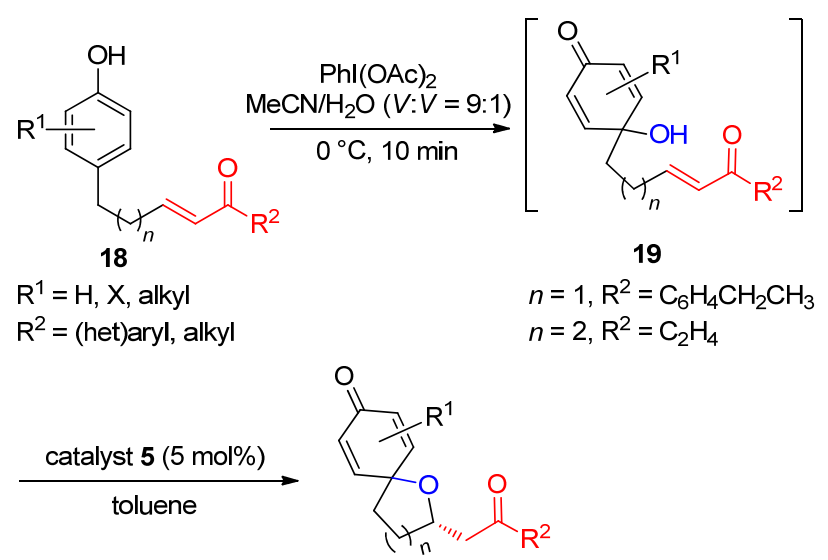

20

up to $85 \%$ yield up to $99 \%$ ee

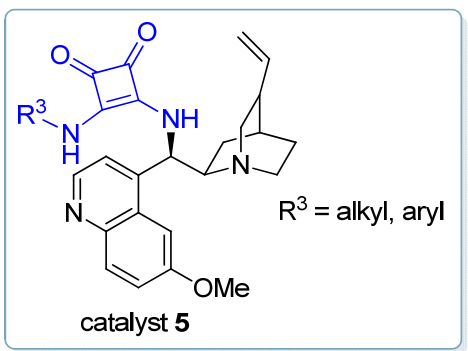

图式 8 金鸡纳碱衍生的方酰胺催化的不对称氧化脱芳/OxaMichael 加成反应

Scheme 8 Asymmetric oxidative dearomatization/Oxa-Michael addition catalyzed by squaramide from cinchona alkaloid

2018 年, Pan 课题组 ${ }^{[19]}$ 利用金鸡纳碱衍生的方酰胺 催化剂 6, 实现了 $\gamma / \delta$-羟基不饱和酮 22 与 $\alpha$-硝基酮 21 的不对称 Michael 加成/酰基转移串联反应(Scheme 9). 在室温条件下，以优异的收率和对映选择性制备了具有 硝基、酮和酯等官能团的化合物 23. 作者认为, 双功能 催化剂 6 中的奎宁环对底物 21 进行活化，同时，四方酰 胺部分通过氢键作用和底物 22 进行结合. 因此，底物 22 中烯烃的 $S i$ 面被催化剂所阻挡, 共轭加成只能选择 性地在 $R e$ 面进行，产生中间体 24. 接着，中间体 24 通 过分子内的半缩酮化产生环状中间体 25. 最后，经过一 步逆 Henry 反应就能生成目标化合物 23.

2-吡啶酮骨架广泛地存在于天然产物和药物中. 2019 年, Hou 和 Tsai 课题组 ${ }^{[20]}$ 报道了双功能催化剂 7 催 化的卤代 2-差基吡啶 26 和底物 27 的对映选择性氮杂- 


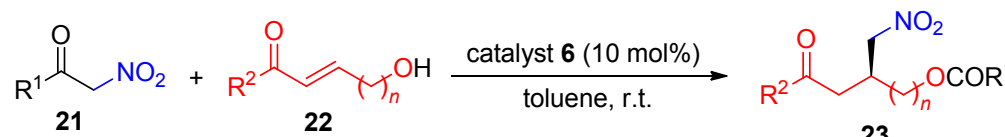

21
22
1

23

$R^{1}=$ (het)aryl, alkyl; $R^{2}=($ het)aryl, alkyl, $h=1,2 \quad$ up to $93 \%$ yield; up to $98 \%$ ee
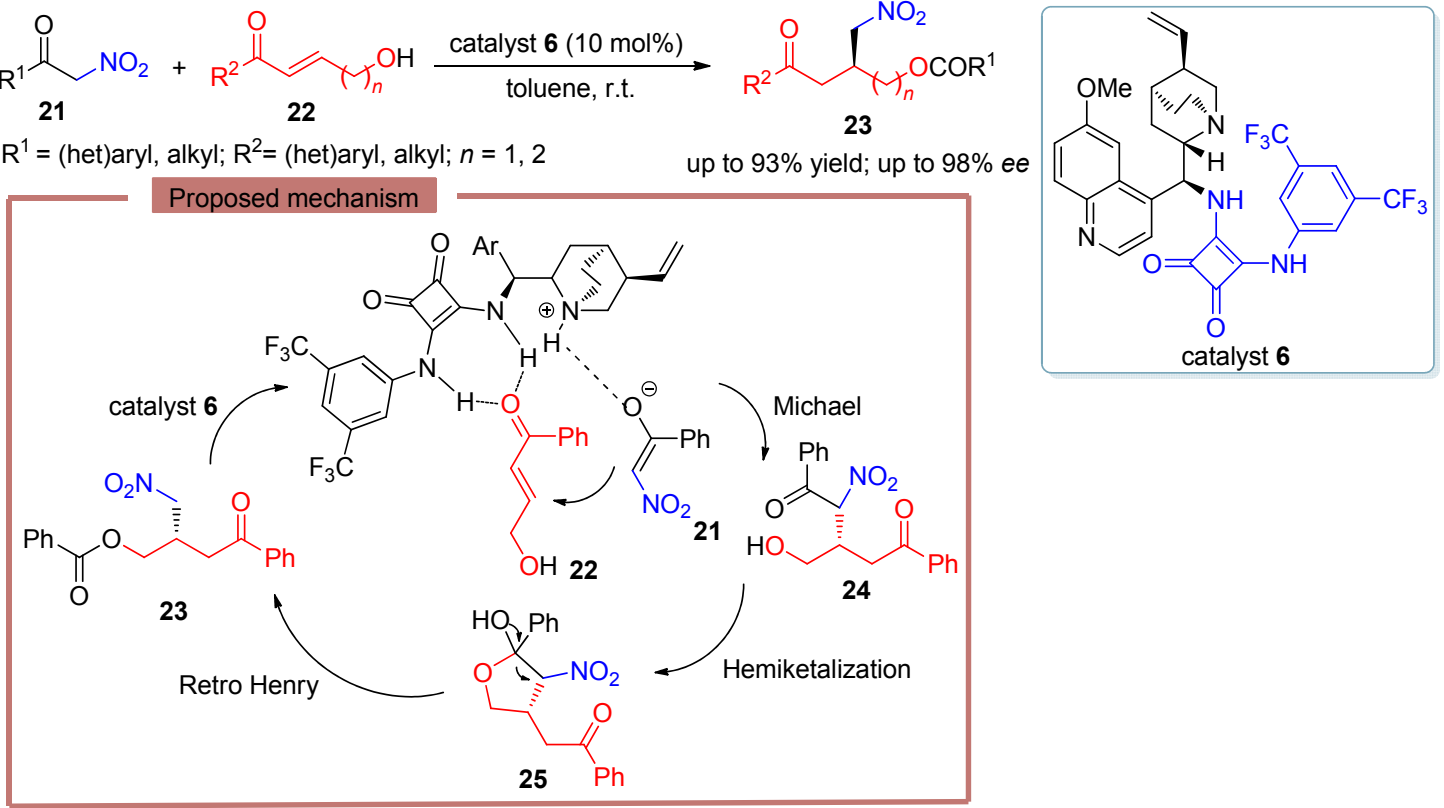

图式 9 金鸡纳碱衍生的四方酰胺催化的不对称多米诺 Michael/酰基转移反应

Scheme 9 Domino Michael/acyl transfer reaction catalyzed by cinchona alkaloid-derived squaramide

Michael 加成反应，以优异的收率和对映选择性得到氮 取代的手性 2-吡啶酮类化合物 28 (Scheme 10). 通过该 方法合成的手性 Michael 加成产物, 经过几步简单的转 化就能实现人鼻病毒蛋白抑制剂的合成. 2018 年, 姜海 洋课题组 ${ }^{[21]}$ 利用金鸡纳碱衍生的伯胺催化剂以及辅助 催化剂苯甲酸实现了 1-硝基-2-苯基乙烯与 2-甲基丙醛 的不对称 Michael 加成反应, 并利用密度泛函方法对反 应机理进行了理论计算研究. 首先, 质子化的手性胺催 化剂与底物醛生成关键的亚胺离子中间体, 随后经历亲 核加成、质子转移和水解三个过程即可得到目标产物. 理论研究表明, 反应的决速步以及立体选择性控制均在 质子转移阶段控制. 详细的机理研究使得人们对 2-甲基 丙醛参与的不对称 Michael 加成反应有了更深的理解.

2020 年, 林宁和鲁桂课题组 ${ }^{[22]}$ 利用金鸡纳碱衍生 的方酰胺双功能催化剂 6 实现了对手性邻四取代二胺 31 的高效合成(Scheme 11). 在传统的不对称 Mannich 反 应中, 醛酮亚胺常作为亲电试剂与亲核试剂来构建碳碳 键, 而在该反应中, 通过极性反转策略, 顺利地将亲电 的环酮亚胺 29 转变为亲核试剂, 接着与另一分子亚胺 30 发生不对称交叉 Mannich 反应，最终以优异的收率、 对映选择性和非对映选择性得到目标产物. 该手性催化 剂在作为氢键供体催化剂之余, 也充当布朗斯特碱诱导 底物发生极性反转. 酮亚胺 29 失去质子后得到亲核性 物种 29-A， 29-A 随后快速与共振式 29-B 达到平衡. 通 过对催化剂与溶剂的篮选, 可能的副反应均可以成功地 避免，且克量级反应也能顺利进行，具有较大的应用价 值.

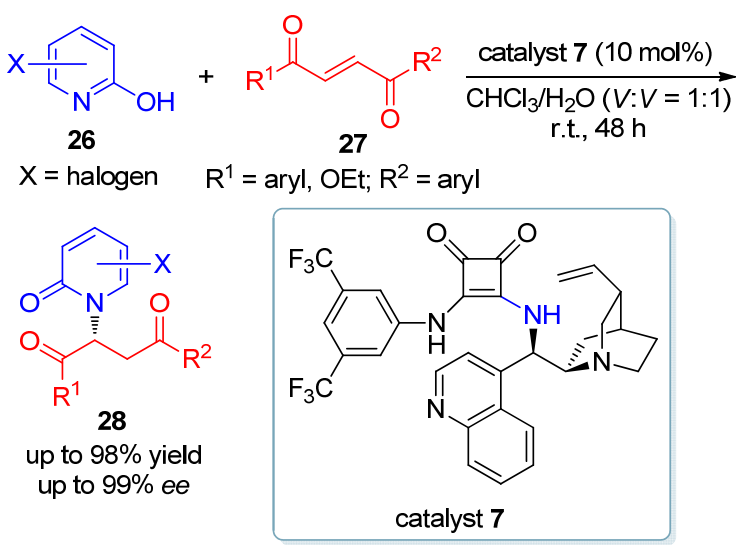

图式 10 金鸡纳碱衍生的四方酰胺催化的不对称氮杂-Michael 加成反应

Scheme 10 Asymmetric aza-Michael addition catalyzed by squaramide from cinchona alkaloid

\section{2 其他类型的金鸡纳衍生物}

金鸡纳生物碱及其衍生物除了作为双功能催化剂 之外，也可以作为布朗斯特碱或路易斯碱催化反应. 另 一方面，近年来对于金鸡纳碱的修饰也不再局限于更换 氢键供体单元，而是另辟蹊径尝试设计出更加丰富多样 的催化剂. 例如, 2018 年, Vilotijevic 课题组 ${ }^{[23}$ 利用金鸡 纳碱衍生的(DHQD) 2 PHAL 催化剂 8 作为路易斯碱来活 化 $N$-甲硅烷基吡咯、吲哚和咔唑类潜亲核试剂 $\mathbf{3 3}$, 通过 与烯丙基氟化物 32 的不对称亲核取代反应，以高对映 选择性实现了此类杂环的 N-烯丙基化反应(Scheme 12). 由于吡咯、吲哚化合物的 N1, C2, C3 位皆具有一定的 
<smiles>[R1]c1ccc2c(c1)N([R])C(=O)/C2=N\CC(F)(F)F</smiles>

29 $\mathrm{R}^{1}=\mathrm{R}^{3}=\mathrm{H}, \mathrm{OMe}, \mathrm{F}, \mathrm{Cl}, \mathrm{Br} ; \mathrm{R}^{2}=\mathrm{R}^{4}=$ alkyl, aryl

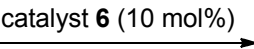
DCM, $-20^{\circ} \mathrm{C}$<smiles>C1CCC1</smiles>

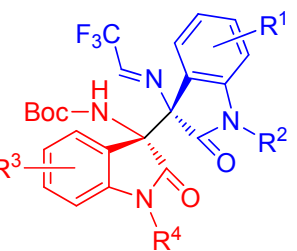

31

up to $98 \%$ yield; up to $99 \%$ ee $d r>20: 1$

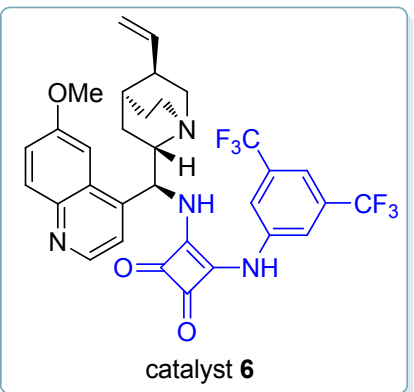

Representative examples<smiles>CN1C(=O)[C@@]2(NC(=O)c3ccccc3)c3ccccc3N(C)C2(NCC(F)(F)F)c2ccccc21</smiles>

$93 \%$ yield, $95 \%$ ee $d r>20: 1$

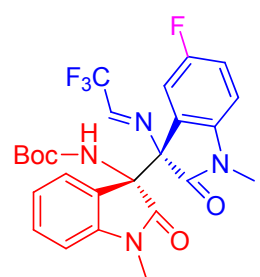

31b

$96 \%$ yield, $88 \%$ ee $d r>20: 1$

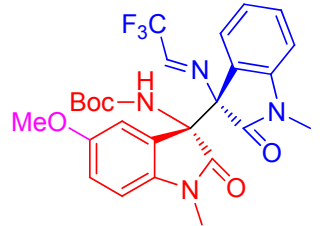

$31 \mathrm{c}$

$90 \%$ yield, $97 \%$ ee $d r>20: 1$

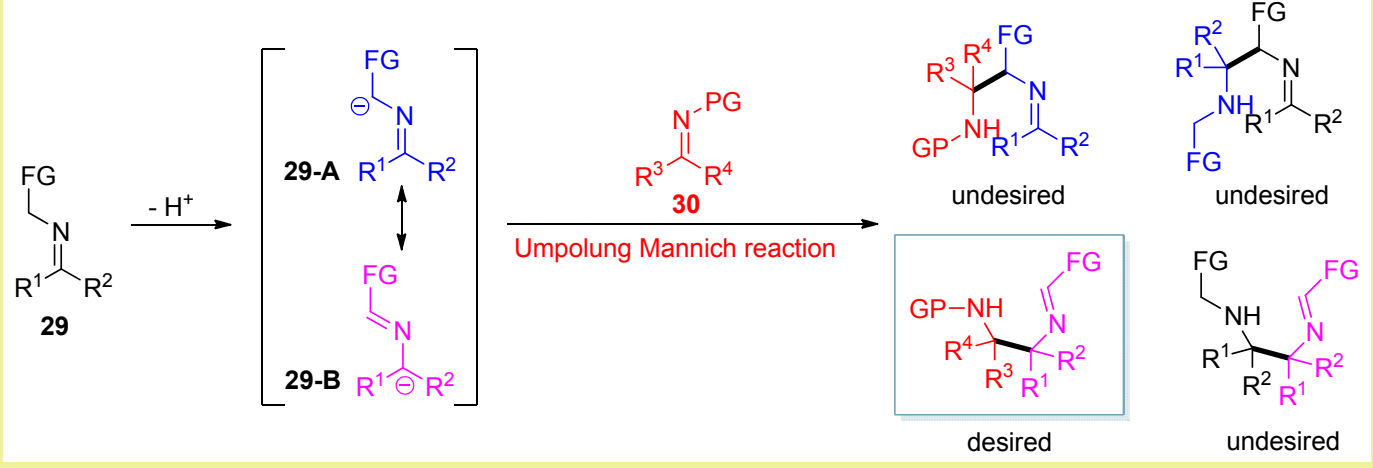

图式 11 金鸡纳碱衍生的四方酰胺催化的不对称极性反转交叉 Mannich 反应

Scheme 11 Asymmetric umpolung cross-Mannich reaction catalyzed by cinchona alkaloid-derived squaramide
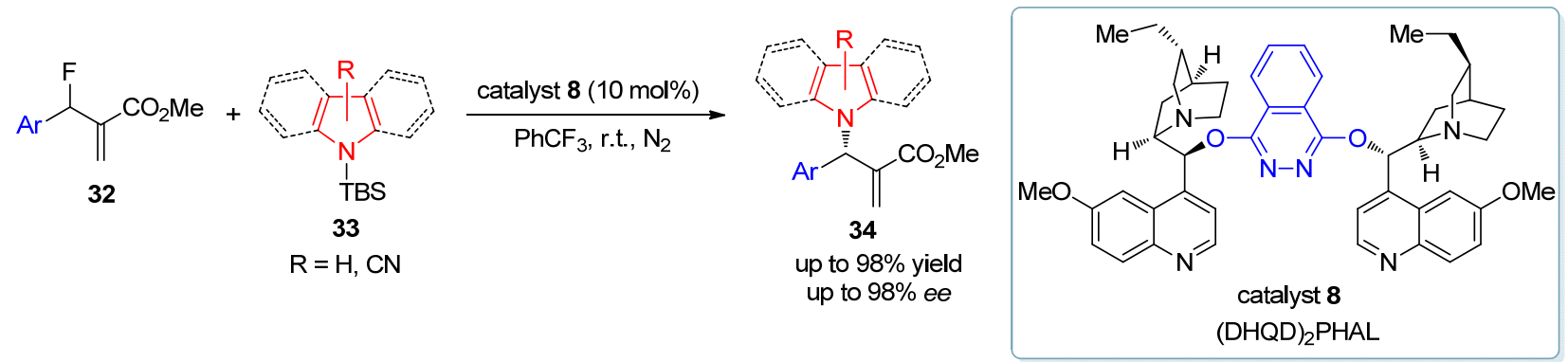

图式 12 金鸡纳碱衍生的(DHQD) 2 PHAL 催化的不对称亲核加成

Scheme 12 Asymmetric nucleophilic addition catalyzed by (DHQD) 2 PHAL

亲核性, 与亲电试剂反应过程中存在 $\mathrm{S}_{\mathrm{N}} 2$ 与 $\mathrm{S}_{\mathrm{N}} 2$ '竞争反 应. 因此, 对亲核、亲电试剂的选择显得尤为重要. 在严 格无氧的反应条件下, 该反应能以优异的收率和对映选 择性得到目标产物 34, 机理研究表明催化剂(DHQD) $2_{2}-$ PHAL 是作为路易斯碱催化该反应.

此外，对于其他新型的金鸡纳碱类似物的催化剂, 也有零星报道. 2016 年, Hiemstra 课题组 ${ }^{[24]}$ 通过对奎宁
桥环扩环或缩环得到了一系列金鸡纳碱衍生的催化剂 9. 2019 年, Itsuno 课题组 ${ }^{[25]}$ 设计了一类金鸡纳碱衍生的 交联手性多聚硅催化剂 10, 这两类催化剂均可以运用 到 Michael 加成反应中, 而催化剂 $\mathbf{1 0}$ 相对催化剂 9 效果 更好. 2019 年, Jindřich 课题组 ${ }^{[26]}$ 设计了一类金鸡纳碱衍 生的 $\alpha$-和 $\beta$-环糊精催化剂 11, 并将其成功应用到不对称 烯丙基氨化反应中. 这些新型金鸡纳碱类似物和衍生物 
的催化剂不仅丰富了金鸡纳碱类催化剂的种类, 使得科 研工作者在选择催化剂时有了更多选择, 同时也给化学 家们带来新的启示, 有望在不久的将来设计出更多、更 高效的有机催化剂(Scheme 13).

\section{3 金鸡纳碱及其衍生物作为手性配体}

20 世纪 80 年代, Sharpless 课题组 ${ }^{[27]}$ 在 $\mathrm{OsO}_{4}$ 氧化烯 烃的基础上, 利用金鸡纳碱衍生的(DHQ) $)_{2}$ PHAL 手性配 体, 首次发展了烯烃的不对称双羟基化反应和胺羟基化 反应，这项开创性的工作给了科研工作者很大的启迪. 化学家们考虑能否将金鸡纳生物碱及其衍生物作为一 类优异的手性配体应用到其他类型反应中. 金鸡纳生物 碱因具有多个手性中心, 且奎宁和喹啉环的刚性结构使 得该物质具有类似酶的手性口袋，从而提供手性环境. 另外, 奎宁桥环上的 $\mathrm{N}$ 原子以及 $\mathrm{C} 9$ 位羟基氧原子均具 有未配对的孤对电子, 可与具有空轨道的金属配位. 值 得一提的是, 金鸡纳生物碱具有多个可修饰位点, 通过 合理的结构修饰即可达到对催化中心的空间和电子效 应进行调控的目的. 配体中的配位原子可以以阴离子的 形式与金属成键, 或提供孤对电子与金属形成路易斯酸 碱加合物, 而配位的方式主要有单齿配位、双齿配位和 三齿配位，这与配位的金属密切相关. 本部分将按照配 位方式展开介绍，而早期发展的烯烃的不对称双羟基化 反应将不作介绍.

\section{1 单齿配位}

2008 年, 游劲松课题组 ${ }^{[28]}$ 基于金属-有机自组装构 建手性催化剂的策略，设计了一类新型的辛可尼啶/钛/ 联菜酚络合物作为手性双功能催化剂, 并成功应用到亚 磷酸二甲酯 35 和醛类化合物 $\mathbf{3 6}$ 的不对称氢磷酰化反应 (Scheme 14). 作者发现，自组装催化剂的对映选择性控 制和催化活性在很大程度上取决于联芸二酚 37 的电性. 当其 3,3'-位的位阻增加时, 反而不利于此反应的进行. 在这项工作中，作者认为自组装构建的手性双功能催化 剂中的钛金属中心作为路易斯酸, 通过与醛底物 36 配 位使其活化. 而金鸡纳生物碱中奎宁环的氮原子作为路 易斯碱，通过氢键作用活化亚磷酸酯，从而使其选择性 地从位阻较小的 $S i$ 面发生反应. 催化剂各组分之间的相 互协同，最后能以优异的收率和对映选择性得到具有重 要生物活性与药物价值的 $\alpha$-羟基磷酸酯 38 .

2009 年, 冯小明课题组 ${ }^{[29]}$ 利用金鸡纳碱/四异丙氧 基钛/联苯酚原位产生催化剂，利用三甲基硅氰(TMS$\mathrm{CN}, 40 \mathrm{a})$ 或者氰基甲酸乙酯(40b)作为氰基源, 以优异的 收率和对映选择性实现了醛、酮、醛亚胺和酮亚胺的不 对称氰基化反应(Scheme 15). 值得注意的是，氧基甲酸 乙酯成功地应用于醛亚胺和酮亚胺的不对称 Strecker 反 应中，以优异的收率和对映选择性得到了一系列的 $\alpha$-氨 基氰化物 42a. 在此反应中, 配体简单易得，操作简便 并且反应条件十分温和，为制备具有重要应用价值的手

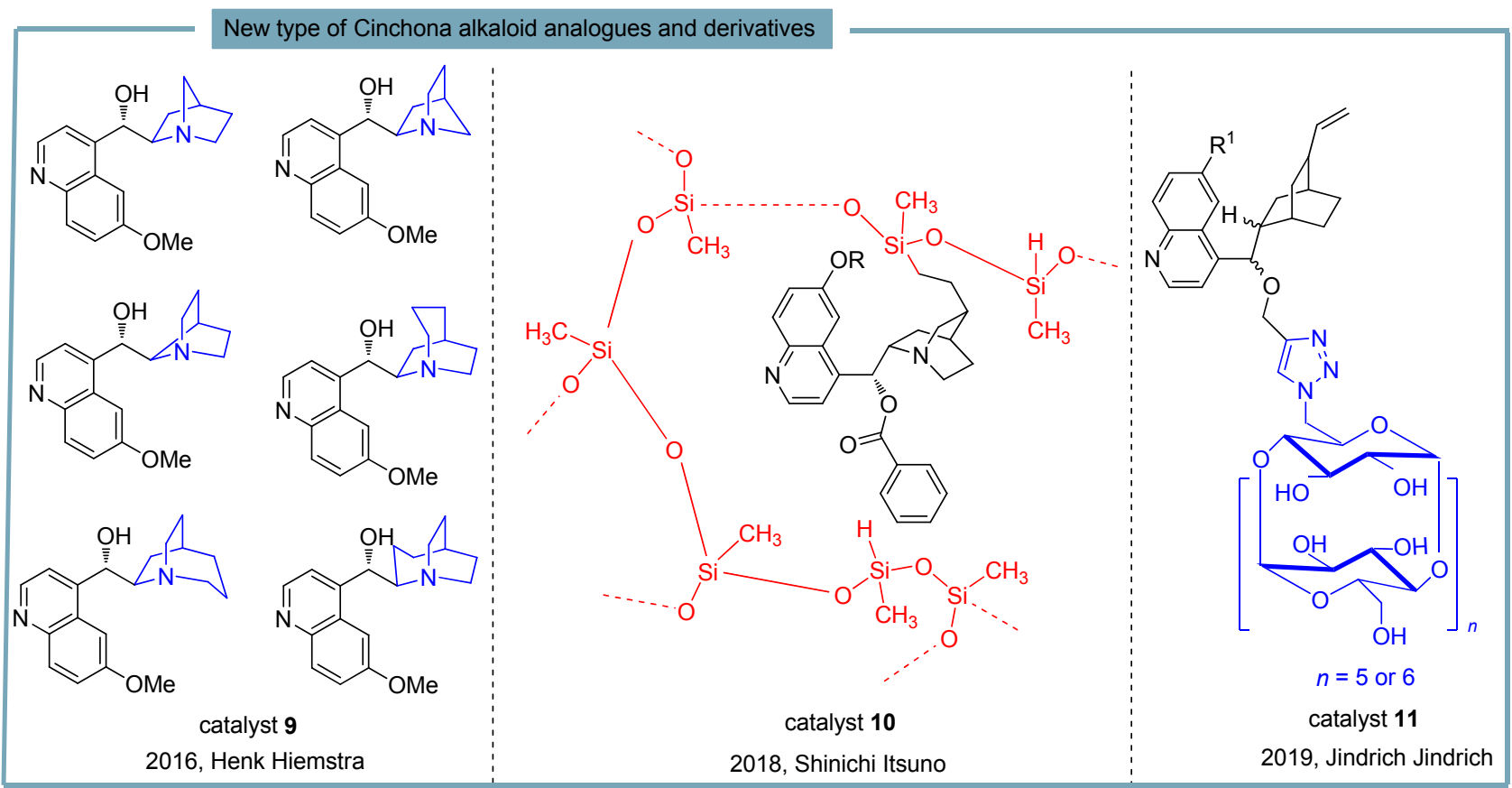

图式 13 奎宁环修饰的奎尼丁类似物新型手性催化剂

Scheme 13 New catalysts of quinidine analogues with ring modifications in the quinuclidine scaffold 


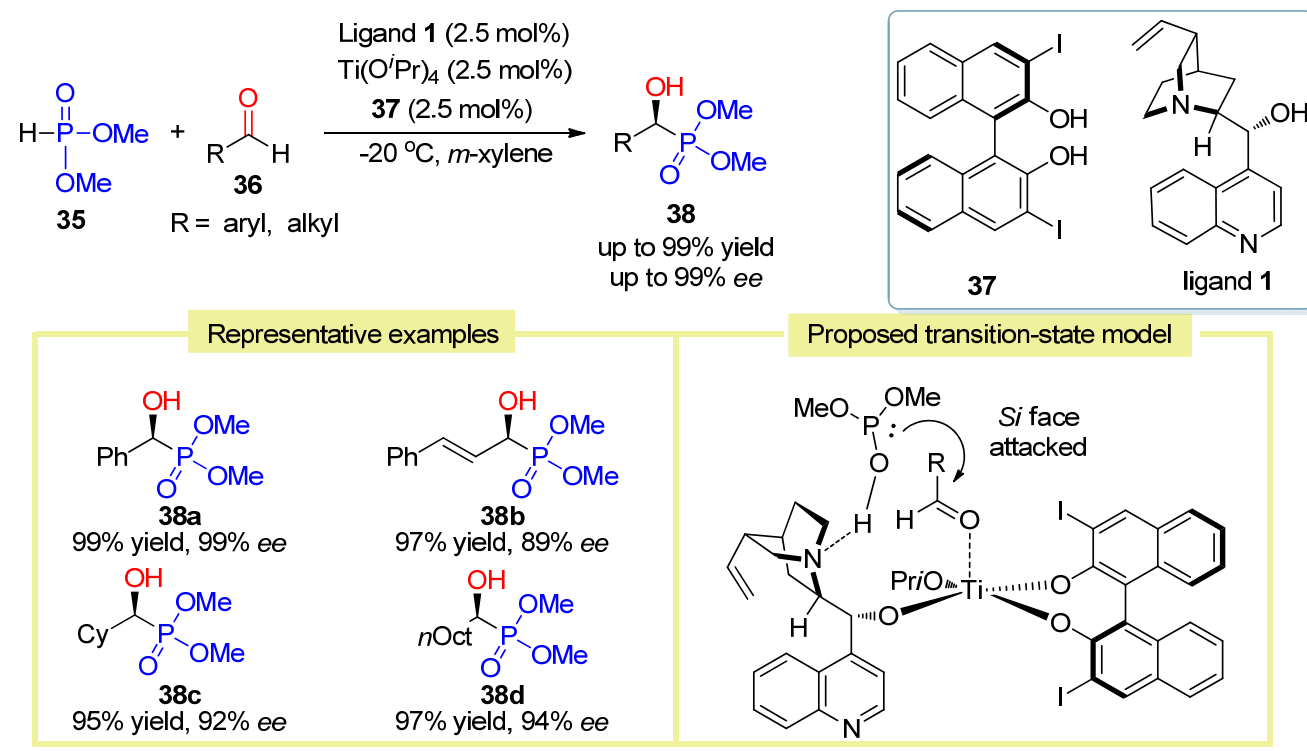

图式 14 钛(IV)络合物催化醛的氢磷酰化反应

Scheme 14 Asymmetric hydrophosphonylation catalyzed by titanium complex

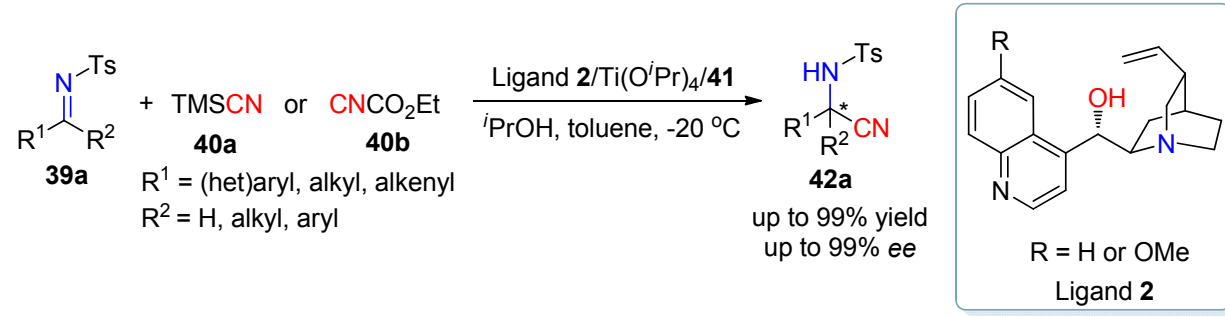

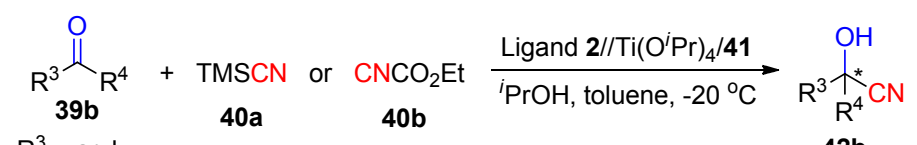

$\mathrm{R}^{3}=$ aryl

42b

$\mathrm{R}^{4}=\mathrm{alkyl}$

up to $99 \%$ yield up to $98 \%$ ee<smiles>[R]c1ccc2nccc(C(O)C3C4CCN3CC4C=C)c2c1</smiles>

L2a: $\mathrm{R}=\mathrm{H}$

L2b: $\mathrm{R}=\mathrm{OMe}$

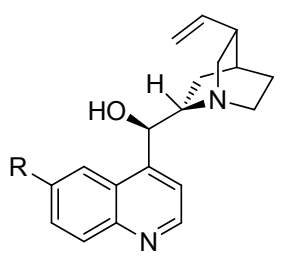

L2c: $\mathrm{R}=\mathrm{H}$

L2d: $\mathrm{R}=\mathrm{OMe}$

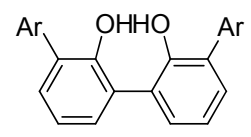

41

41a: $\mathrm{Ar}=2$-naphthyl 41b: $A r=1$-naphthyl
Proposed catalytic model

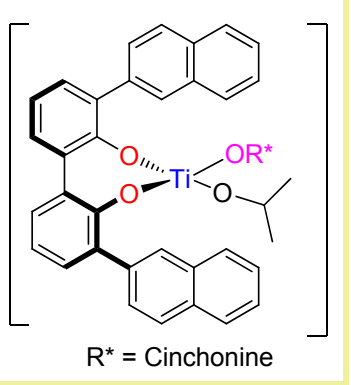

图式 15 钛(IV)络合物催化的不对称氰基化反应

Scheme 15 Titanium(IV)/complex-catalyzed asymmetric cyanation

性氰醇和 $\alpha$-胺基氰化物提供了一个有效的途径. 通过控 制实验和核磁实验分析，作者发现金鸡纳生物碱和联苯 酚中的所有羟基均和金属钛发生配位，形成真正的催化 剂物种. 联苯酚配体 3,3'-位上的大位阻取代基对反应高 对映选择性的实现至关重要. 根据控制实验和核磁实验 分析, 作者也确证了联苯酚配体在催化剂中绝对构型为 $S$ 构型. 另外, 作者证明了添加剂异丙醇 $\left({ }^{i} \mathrm{PrOH}\right)$ 在催化
剂的作用下，能够和氰基源发生反应，产生真正的氰基 化试剂氢氰酸( $\mathrm{HCN})$, 在此过程中, 金鸡纳生物碱中的 三级胺对于氢氰酸的产生至关重要. 此外, 其也作为路 易斯碱来活化氢氰酸.

2013 年, 冯小明和胡常伟等 ${ }^{[30]}$ 将氰源替换为氢氰 酸，在类似的体系下同样研究了该反应(Scheme 16). 而 在该工作中，作者借助密度泛函理论(DFT)计算和分层 
计算(ONIOM)模拟更进一步地解释了机理中存在的问 题. 作者提出氢氰酸的异构化过程是该反应的决速步, 而碳一碳键生成则是该反应过程中立体选择性的控制步 骤. 在不对称诱导过程中, 通过与中心金属钛的协同作 用, 手性金鸡纳碱配体向轴向柔性非手性双酚配体进行 手性转移，这一机理细节的完善使得人们对该反应有了 更深的了解.

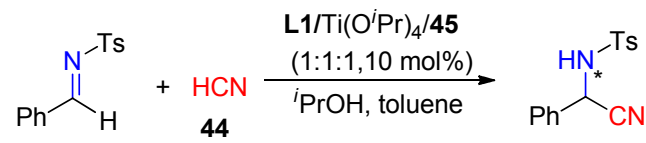

43

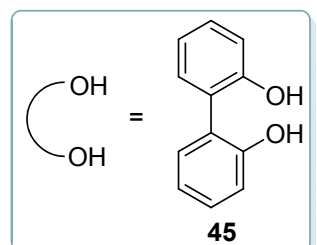

46

Origin of stereoselectivity

Cinchonine

(Lewis base)

Ti metal centre $\bigcirc$-...-.-HCN Re-attack (Lewis acid)

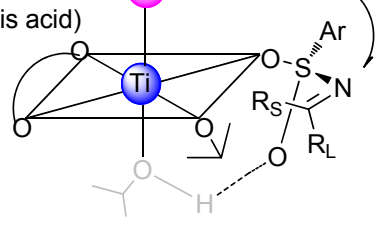

Cinchonine

(Lewis base)

Ti metal centre $\bigcirc$-...- HCN $\longrightarrow$ Si-attack (Lewis acid)

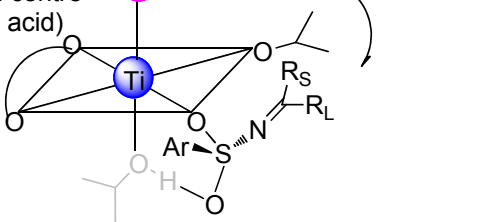

图式 16 钛(IV)络合物催化的氰基化机理研究

Scheme 16 Mechanism of titanium(IV)-catalyzed cyanation

2009 年, 冯小明课题组 ${ }^{[31]}$ 进一步拓展了该催化体 系的实用性, 作者利用辛可尼/钛/ $(S)$-联菱酚的催化体系 实现了醛 47 与重氮乙酸乙酯 48 的不对称的 Aldol 反应, 得到一类具有生物活性醇的重要前体重氮- $\beta$-羟基酯 $\mathbf{5 0}$ (Scheme 17a). 2010 年, 冯小明课题组 ${ }^{[32]}$ 又利用类似的 催化体系实现了㲵基甲酸酯 $40 \mathrm{~b}$ 与 $\alpha, \beta$-不饱和羧酸酯 51 的不对称氰基化反应(Scheme 17b). 在无溶剂和温和的 反应条件下，以优异的收率和对映选择性获得目标产物 52, 且该产物具有较高的附加价值.

另外, 冯小明课题组 ${ }^{[33]}$ 还发展了一种有效的奎宁$\mathrm{Al}\left(\mathrm{O}^{i} \mathrm{Pr}\right)_{3}$ 络合物催化体系, 实现了丙二腈 54 与查尔酮 53 的不对称 Michael 加成反应(Scheme 18). 并且产物可 (b)<smiles>[R]C=C(OCC)OCC[N+](=O)OCC</smiles><smiles>[R]OC(OCC)C(OCC)C([R])C#N</smiles>

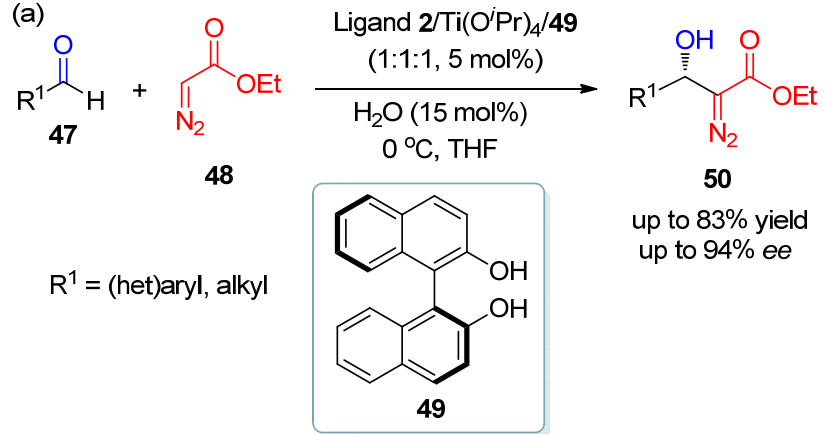

Ligand $2 / \mathrm{Ti}\left(\mathrm{O}^{\prime} \mathrm{Pr}\right)_{4} / \mathbf{4 1 c}$ or $\mathbf{4 1 d}$
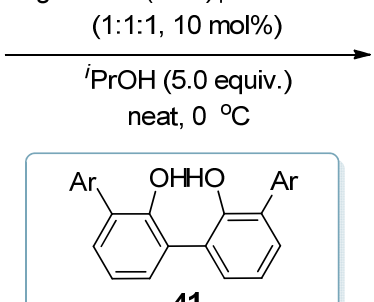

41

41c: Ar $=9$-phenanthryl 41d: $\mathrm{Ar}=2,6-(\mathrm{MeO})_{2} \mathrm{C}_{6} \mathrm{H}_{3}$

$$
\mathrm{R}^{2}=\text { (het)aryl, alkyl }
$$

Elaboration of product 52a<smiles>CCOC(=O)C(C(=O)OCC)[C@@H](C#N)c1ccccc1</smiles>

(2) $m$-xylene, $140^{\circ} \mathrm{C}$

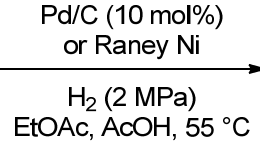

$\mathrm{AAc}, \mathrm{AcOH}, 55^{\circ} \mathrm{C}$

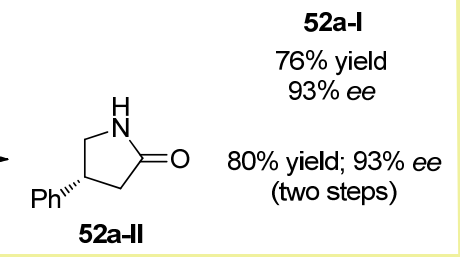

图式 17 钛催化的不对称 Aldol 和 Michael 加成反应 Scheme 17 Asymmetric aldol, Michael reaction catalyzed by titanium

以进一步转为在生物化学和药学中十分有用的四氢吡 喃类衍生物. 作者认为奎宁在该反应中扮演了两个角 色: 一方面, 奎宁环中三级胺部分作为布朗斯特碱活化 底物丙二腈; 另一方面，羟基作为手性配体与三价铝作 用. 作者也给出了可能的催化活化模式.

2012 年, Glorius 课题组 ${ }^{[34]}$ 报道了奎宁作为手性配 体参与的钯催化环酮 56 和芳基溴代物或者碘代物 57 的 不对称 $\alpha$-芳基化反应(Scheme 19). 与传统常用的钯/联 荎酚催化体系相比，该反应具有更好的立体选择性，其 $e e$ 值最高可达到 $93 \%$. 此外, 他们提出了三种可能的作 用模型，而基于控制实验作者更认同 $\mathrm{B}$ 模型：奎宁作为 单齿配体(氮原子与钯配位)的同时也通过弱相互作用与 底物结合. 


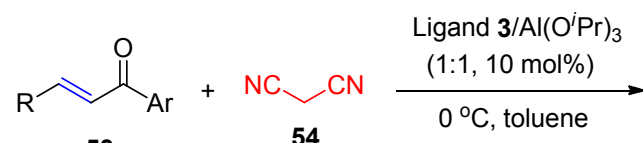

53

54<smiles>[R]C(CC(=O)Br)C(C#N)C#N</smiles>

55

up to $97 \%$ yield up to $93 \%$ ee

$\mathrm{R}=$ (het)aryl alkyl, alkenyl
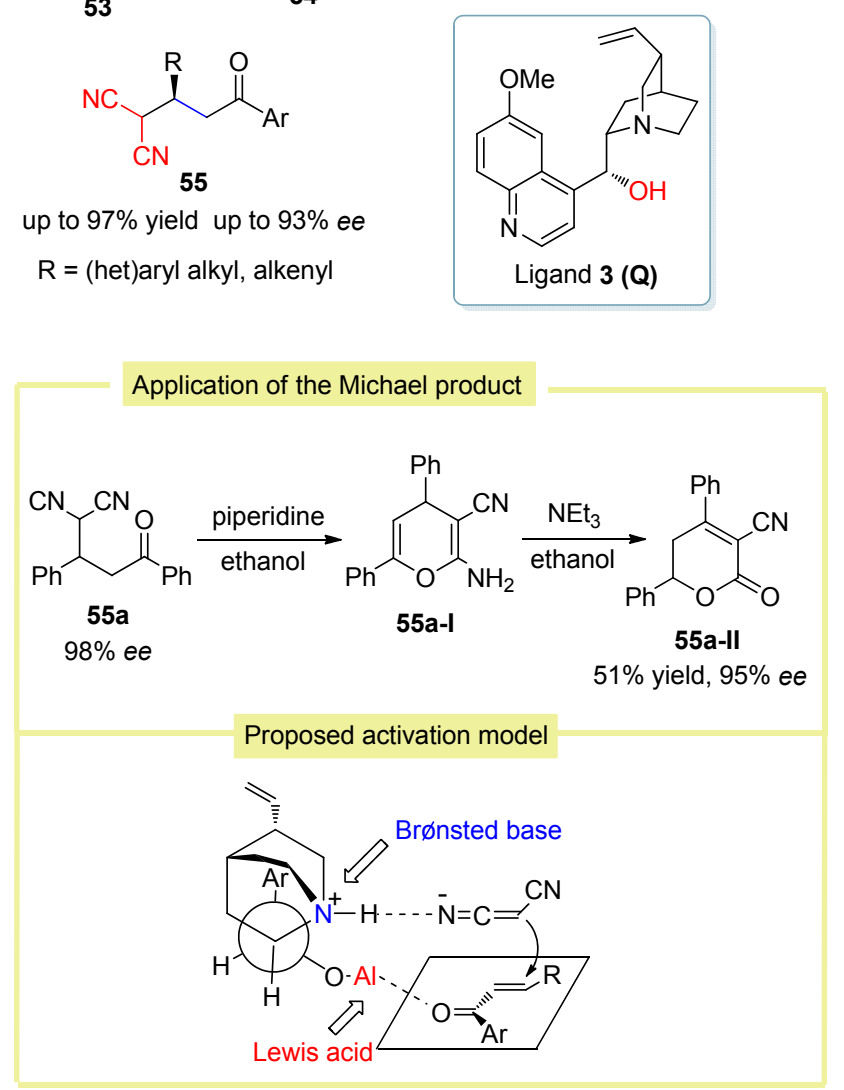

图式 18 铝-喹宁络合物催化的 Michael 加成反应

Scheme 18 Michael addition reaction catalyzed by quinine-Al$\left(\mathrm{O}^{i} \mathrm{Pr}\right)_{3}$ complex

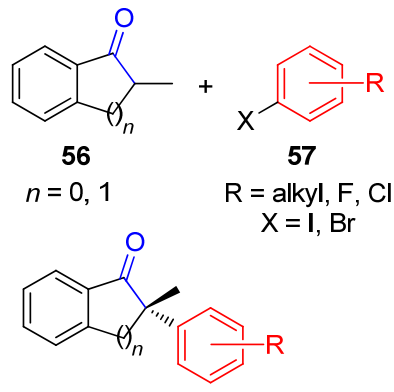

58

up to $91 \%$ yield up to $93 \%$ ee

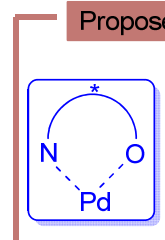

A

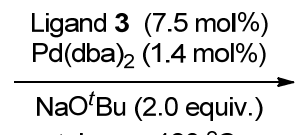

toluene, $100^{\circ} \mathrm{C}$

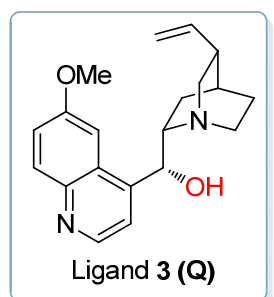

图式 19 钯/金鸡纳碱络合物催化环酮的不对称 $\alpha$-芳基化反应

Scheme 19 Asymmetric $\alpha$-arylation of cycloketones catalyzed by palladium/cinchona alkaloid

\section{2 双齿配位}

\subsubsection{N,N 配位}

手性醇类化合物骨架广泛存在于许多天然产物和 药物分子中，而潜手性羰基化合物被认为是构建手性醇 类化合物的最佳原料之一，因而受到化学家广泛关注. 在过去的二十年中，陆续发展了手性二胺配体或者氮磷 配体，通过与钌、铑、铱、铝、钐等金属的结合实现羰 基化合物的不对称氢转移化反应. 2003 年，Arvidsson 等 ${ }^{[35}$ ]报道了以金属铱作为催化剂, 具有奎宁环结构单 元的手性二胺 4 为外加配体，异丙醇作为溶剂的条件下， 实现了苯乙酮 59 的高效还原，其 ee 值最高可达 95\% (Scheme 20a). 随后, 张生勇课题组 ${ }^{[36]}$ 以 $[\operatorname{Ir}(\mathrm{COD}) \mathrm{Cl}]_{2}$ 作 为金属前体，9-氨基金鸡纳生物碱作为配体，异丙醇作 为氢源，也实现了芳基酮的不对称转移氢化反应. 相比 之前的工作，产物的 ee 值有所上升，但产率有所下降 (Scheme 20b).

(a)

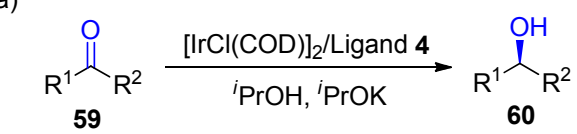

$\mathrm{R}^{1}=$ aryl; $\mathrm{R}^{2}=$ alkyl $\quad$ up to $99 \%$ yield; up to $95 \%$ ee

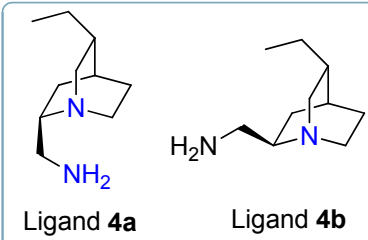

(b)
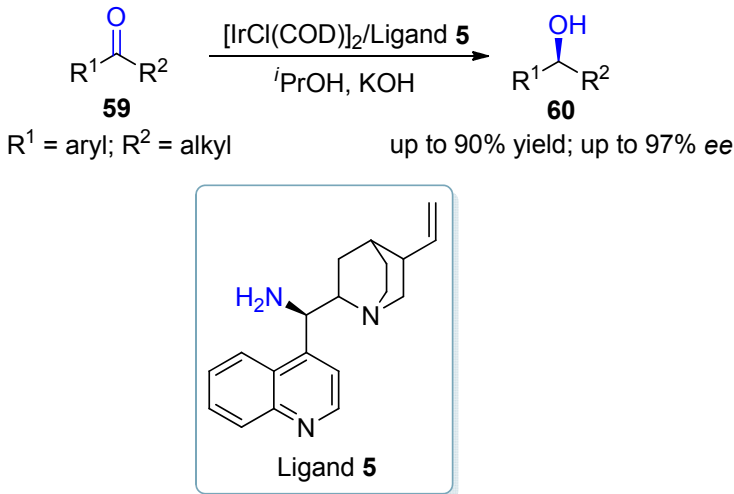

图式 20 铱催化羰基化合物的不对称转移氢化反应

Scheme 20 Asymmetric transfer hydrogenation reaction of carbonyl compounds catalyzed by iridium

手性 $\beta$-氨基磷酸及其衍生物由于具有独特的生物 活性以及可作为配体参与不对称催化，因此其立体选择 性地合成受到了许多化学家们的密切关注. 2012 年, Nakamura 课题 组 ${ }^{[37]}$ 利用金鸡纳碱衍生的吡啶甲酰胺 配体 6, 在路易斯酸二乙基锌 $\left(\mathrm{Et}_{2} \mathrm{Zn}\right)$ 催化下，实现了氮 
杂环丙烷 61 与亚磷酸酯 62 的不对称氢磷酰化反应. 产 物 $\beta$-胺基亚磷酸酯类化合物 63a 经过简单的转换即可得 到高附加值的 $\beta$-氨基磷酸, 并且无对映选择性损失. 此 外, 他们结合 ESI-MS 分析所捕获到的关键中间体和产 物的绝对构型, 给出了反应过程中可能的过渡态 (Scheme 21).

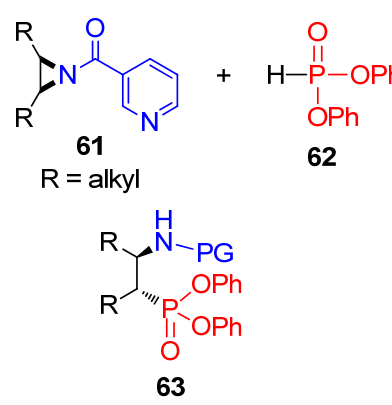

up to $91 \%$ yield; up to $99 \%$ ee
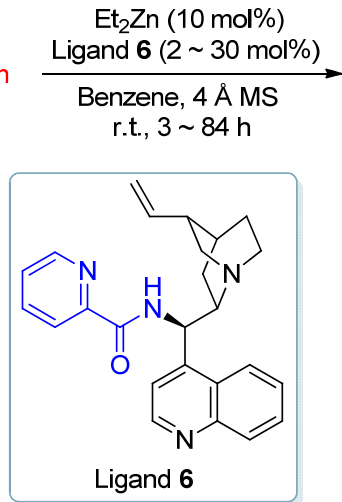

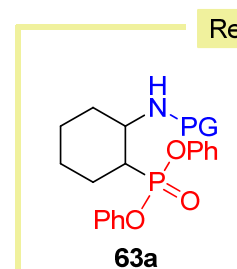

$63 a$

$94 \%$ yield, $98 \%$ ee<smiles>O=C(NC1CN(C(=O)OCc2ccccc2)CC1P(=O)(Oc1ccccc1)c1ccccc1)c1ccccc1</smiles>

63b

$64 \%$ yield, $97 \%$ ee

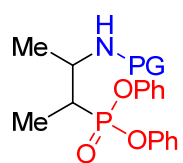

$63 c$
$90 \%$ yield, $99 \%$ ee

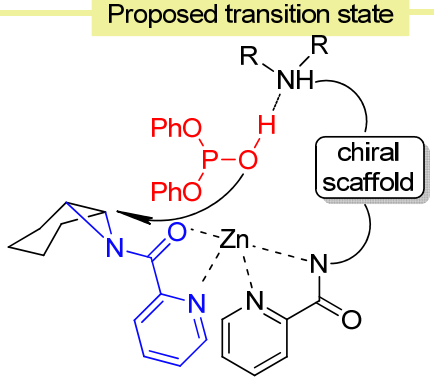

Transformation of product $63 a$<smiles>O=C(N[C@H]1CCCC[C@H]1P(=O)(Oc1ccccc1)Oc1ccccc1)c1ccccn1</smiles>

(1R,2R)-63d, >99\% ee

(1) conc. $\mathrm{HCl}$, reflux, $20 \mathrm{~h}$

(2) propylene oxide, EtOH $97 \%$ yield

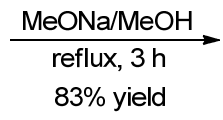

$3 \%$ yield

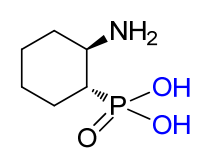

63d-II, $>99 \%$ ee

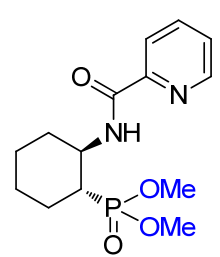

63d-I

图式 21 锌/吡啶甲酰胺络合物催化氮杂环丙烷的氢磷酰化反 应

Scheme 21 Asymmetric hydrophosphorylation of aziridines catalyzed by $\mathrm{Zn}(\mathrm{II})$-cinchona alkaloid amide

2014 年, Nakamura 课题组 ${ }^{[38]}$ 利用金鸡纳碱衍生的

吡啶甲酰胺类配体 $7 / \mathrm{Cu}(\mathrm{OTf})_{2}$ 的催化体系，顺利地实现 了酮亚胺 64 与 $\alpha$-异氰酸酯 65 的不对称 Mannich 反应 (Scheme 22). 与之前工作不同的是, 金鸡纳碱衍生的吡 啶甲酰胺配体中，吡啶环 4-位增加取代基可以明显改善 反应的非对映选择性. 通过篮选后发现，4-位连有三氟 甲基时效果最佳，其 $d r$ 值最高可达 $92 ： 8$. 该反应以中 等收率和高对映选择性, 高非对映选择性有效地合成了 $\alpha, \beta$-二氨基酸的重要前体手性咪唑啉类化合物 66, 底物 普适性良好，适用于各种芳基烷基取代的酮亚胺. 作者 也给出了具体的催化模式. 随后该团队 ${ }^{[39]}$ 还实现了 $\alpha$ -

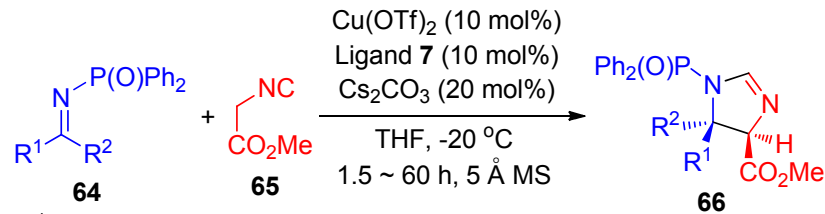

$\mathrm{R}^{1}=$ (het)aryl, alkyl

$\mathrm{R}^{2}=\mathrm{Mel}, \mathrm{Et}$

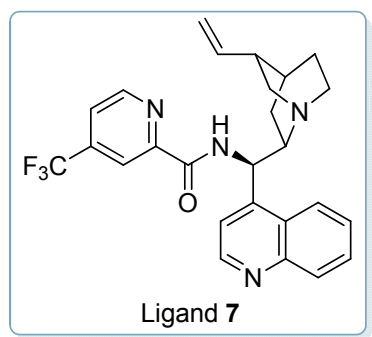

up to $78 \%$ yield up to $99 \%$ ee 28:72 92:8 $d r$

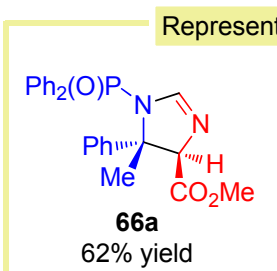

$99 \%$ ee, $d r=92: 8$

$\mathrm{Ph}_{2}(\mathrm{O}) \mathrm{P}$<smiles>COC(=O)[C@H]1N=CN(POc2ccccc2)[C@@]1(C)c1ccco1</smiles>

66c

$52 \%$ yield

$93 \%$ ee, $d r=92: 8$

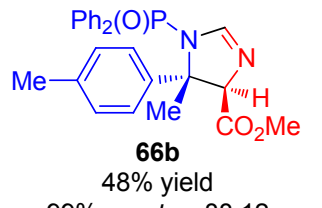

$99 \%$ ee, $d r=88: 12$

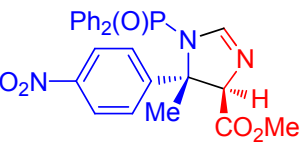

66d

$51 \%$ yield

Proposed transition state

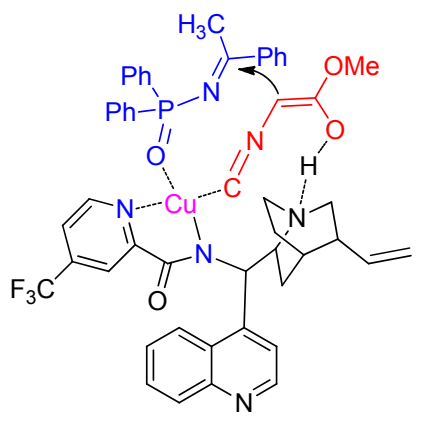

图式 22 铜(II)/吡啶甲酰胺络合物催化不对称 Mannich 反应 Scheme 22 Asymmetric Mannich reaction catalyzed by $\mathrm{Cu}(\mathrm{II})-$ cinchona alkaloid amide 
取代异氧酸酯与酮亚胺的直接不对称 Mannich 反应, 进 一步拓展了该类催化体系的反应适用范围.

2013 年, 宋玲课题组 ${ }^{[40]}$ 设计了一类由金鸡纳碱衍 生的新型手性磷酰胺配体 $\mathbf{8}$, 并将其成功应用到二乙基 锌 $\left(\mathrm{Et}_{2} \mathrm{Zn}\right)$ 与醛 36 的不对称加成反应中 (Scheme 23). 通 过对配体的篎选, 他们发现手性磷酰胺配体中喹啉环 C6 位甲氧基对于催化剂的催化效率和立体选择性有着 重要的影响. 在甲苯与二氯甲烷的混合溶剂中, 能以高 达 $99 \%$ 的收率和 $e e$ 值得到具有重要价值的手性仲醇. 对于可能的活化模式, 作者认为手性配体 $\mathbf{L 8}$ 和二乙基 锌 $\left(\mathrm{Et}_{2} \mathrm{Zn}\right)$ 反应生成手性 $\mathbf{L 8}-\mathrm{Zn}$ 复合物. 该复合物是一种 多功能的催化剂, 其含有 $N, N$-螯合的锌金属中心作为路 易斯酸来活化苯甲醛, 来自磷酰胺基团的 $\mathrm{P}=\mathrm{O}$ 部分作 为共轭的路易斯碱, 通过 $\mathrm{Zn}-\mathrm{N}-\mathrm{P}=\mathrm{O}$ 键之间的共轭 作用活化二乙基锌 $\left(\mathrm{Et}_{2} \mathrm{Zn}\right)$. 手性磷酰胺配体中喹啉环 C6 位甲氧基团作为第二个路易斯碱来协助 $\mathrm{P}=\mathrm{O}$ 部分 活化二乙基锌, 进一步增强其亲核性, 从而获得更高的 反应性, 并使过渡态的构型更加刚性, 同时具有更好的 对映选择性.
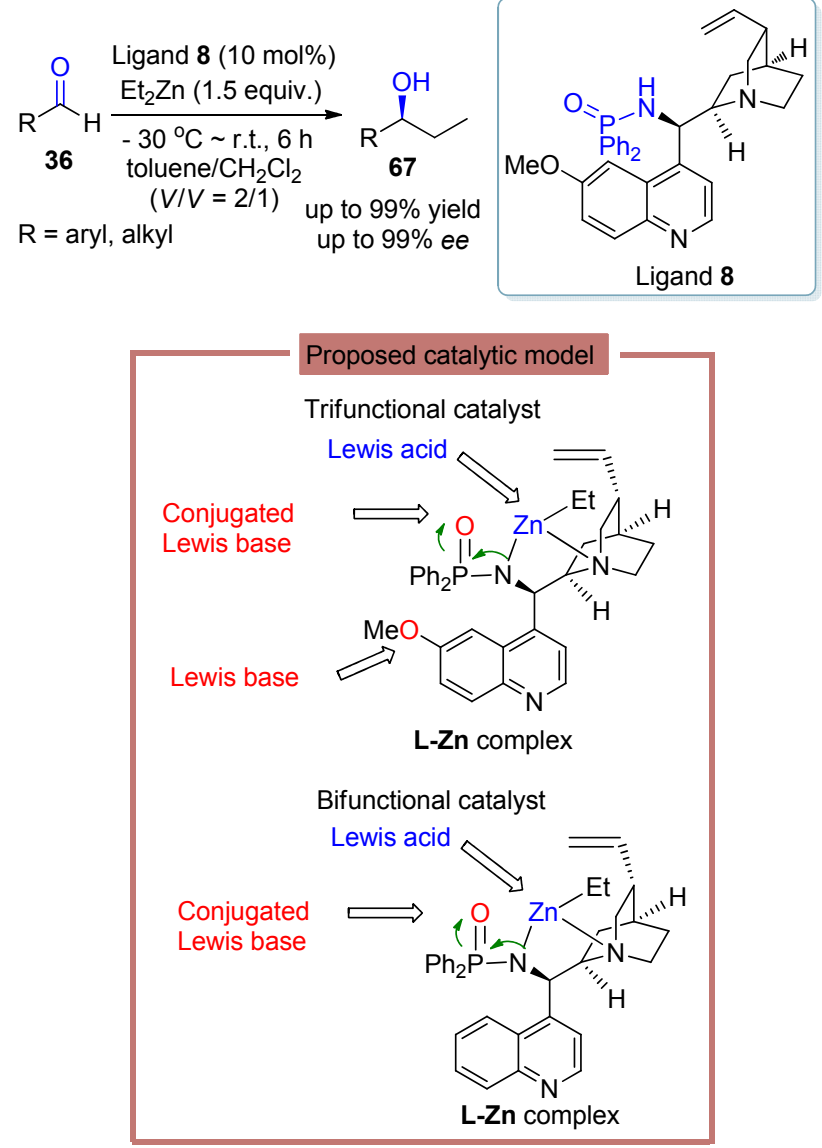

图式 23 磷酰胺-锌(II)复合物催化二乙基锌与醛的不对称加 成反应

Scheme 23 Asymmetric additions of diethylzinc to aldehydes catalyzed phosphoramide-Zn(II) complexes
同年，王永梅和黄耀东等 ${ }^{[41]}$ 基于手性分子结合(非) 手性分子构建手性配体这一策略，从简单易得的原料出 发, 只需一步, 就能够以相对较高的收率制备得到一系 列新的金鸡纳碱衍生的联吡啶配体 9, 并成功应用到铜 催化的醛 36 的不对称 Henry 反应中(Scheme 24). 该催 化体系可以适用于多种芳香、杂芳香和脂肪醛，以高收 率和高对映选择性得到相应的硝基烷醇类化合物. 此 外，他们基于 ${ }^{1} \mathrm{H}$ NMR、DFT 计算研究，给出了可能的 催化模式: Cu-L9 复合物在平面上有四个强的配位点, 在顶端有两个弱的配位点, 手性配体联吡啶片段中两个 氮原子占据两个相邻的强配位点. 为了最大程度活化底 物，亲核试剂硝基甲烷 7 垂直于催化平面与铜作用，而 底物醛在平面上与作为路易斯酸的铜配位，从而被活 化. 因为 C6 位上甲氧基的空间位阻效应，底物醛中的

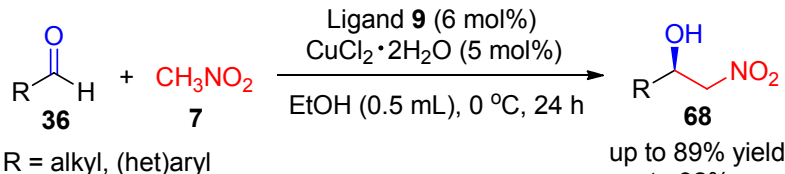

$\mathrm{R}=$ alkyl, (het)aryl

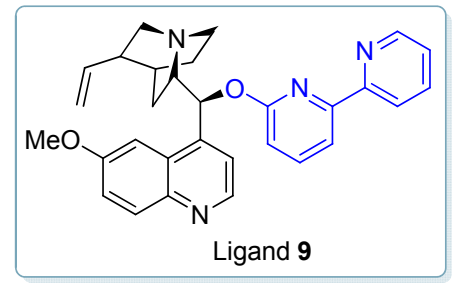
up to $92 \%$ ee

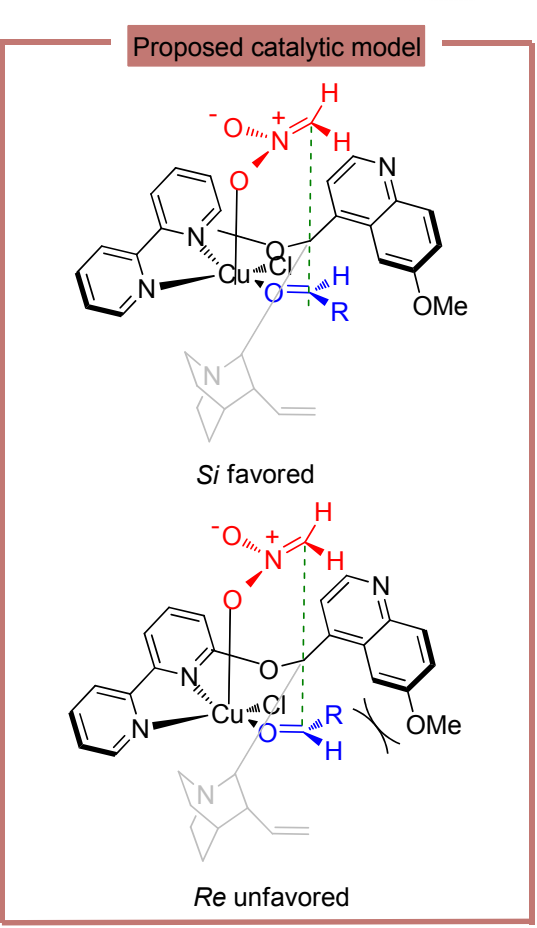

图式 24 铜/含金鸡纳碱联吡啶络合物催化的不对称 Henry 反 应

Scheme 24 Asymmetric Henry reaction catalyzed by copper/ cinchona alkaloid-derived bipyridine 
大位阻基团远离甲氧基，指向空位. 同时，铜配合物的 顶端被硝基甲烷占据，因此，硝基甲烷从醛的 $S i$ 面进攻， 进而得到 $R$ 构型的产物.

2018 年, 刘心元课题组 ${ }^{[42]}$ 利用合理设计的金鸡纳 碱衍生的手性磺酰胺化合物 $\mathbf{1 0}$ 作为配体, 以 Togni's 试 剂 70 为三氟甲基自由基源, 成功地实现了铜催化的烯 基朊 69 的不对称自由基氧三氟甲基化反应，以优异的 收率和对映选择性直接获得具有 $\alpha$-四取代中心的含 $\mathrm{CF}_{3}$ 的异啞唑啉产物 (Scheme 25). 该产物经过简单地转换 即可合成高附加值的 1,3-氨基醇手性化合物. 此外, 他 们通过对照实验、FTIR 光谱数据和高分辨质谱分析, 作 者认为 $\mathbf{L 1 0}$ 中了奎宁环上的叔胺和磺酰胺阴离子作为 $N, N$-双齿配体, 与铜配位形成五元双螯合配合物. 并在 此基础上提出了可能的反应机理：铜和 $\mathbf{L 1 0}$ 通过配体交 换，原位生成真正的活性催化剂双螯合的 $\mathrm{Cu}(\mathrm{I})$ 络合物 10-A，与底物 70 发生单电子转移产生 $\mathrm{Cu}(\mathrm{II})$ 络合物 10-B 和 $\mathrm{CF}_{3}$ 自由基. $\mathrm{CF}_{3}$ 自由基迅速对底物 69 中的烯烃进行 加成，产生自由基中间体 69-A, 69-A 与 $\mathrm{Cu}(\mathrm{II})$ 络合物 10-B 通过配体交换形成中间体 69-B. 随后发生分子内 的氧化还原反应生成 $\mathrm{Cu}(\mathrm{III})$ 物种 $69-\mathrm{C}$, 再经过还原消 除得到最终产物 71. 但是作者也不能排除磺酰胺上的
氮阴离子和铜单齿配位， L10 中奎宁环上的叔胺作为碱 协同活化肟差基这一过程.

近年来，自由基介导的末端烯烃的不对称双官能化 反应取得了迅猛的发展，但是，对于自由基介导的非末 端烯烃的不对称双官能团化反应(产生两个相邻的立体 中心)仍然具有挑战性. 2020 年, 刘心元课题组 ${ }^{[43]}$ 利用该 团队发展的铜一金鸡纳碱衍生的手性磺酰胺配体 11 络合 物作为强的单电子还原催化剂, 实现了 $\beta, \gamma$-不饱和酮肜 72 与磺酰氯 73 的不对称自由基氧磺酰化反应(Scheme 26). 该方法反应条件温和，适用于一系列含有端烯或 非端烯的 $\beta, \gamma$-不饱和酮肟，以及(杂)芳基或烷基取代的 磺酰氯，以优异的收率、对映选择性和非对映选择性得 到含有磺酰基取代的异噁唑啉类产物 74.

通过机理实验和 DFT 理论计算，作者提出了可能 的反应机理(Scheme 27): 原位产生的双螯合的 $\mathrm{Cu}(\mathrm{I})$ 络 合物 11-A 具有强的还原能力, 首先和底物磺酰氯 73 发 生单电子转移产生相应的 $\mathrm{Cu}(\mathrm{II})$ 络合物 11-B 和磺酰基 自由基. 接着, 11-B 通过脱去底物 72 中的酮肟上的质子 与其络合，形成中间体 72-A. 随后，磺酰基自由基对中 间体 72-A 中的烯烃进行加成，此过程是快速可逆的，产 生烷基自由基中间体 72-B 和 72-B'. 在 Curtin-Hammett<smiles>[R]C(=C)CC([R])=NO</smiles>

69

$\mathrm{R}^{1}=$ (het)aryl; $\mathrm{R}^{2}=$ (het)aryl, alkenyl

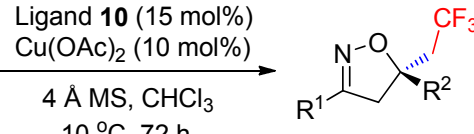

71

up to $99 \%$ yield, up to $92 \%$ ee

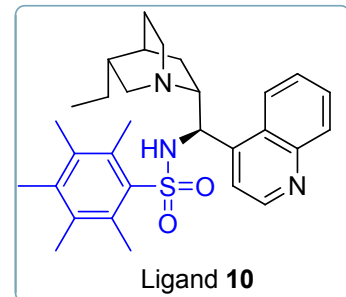

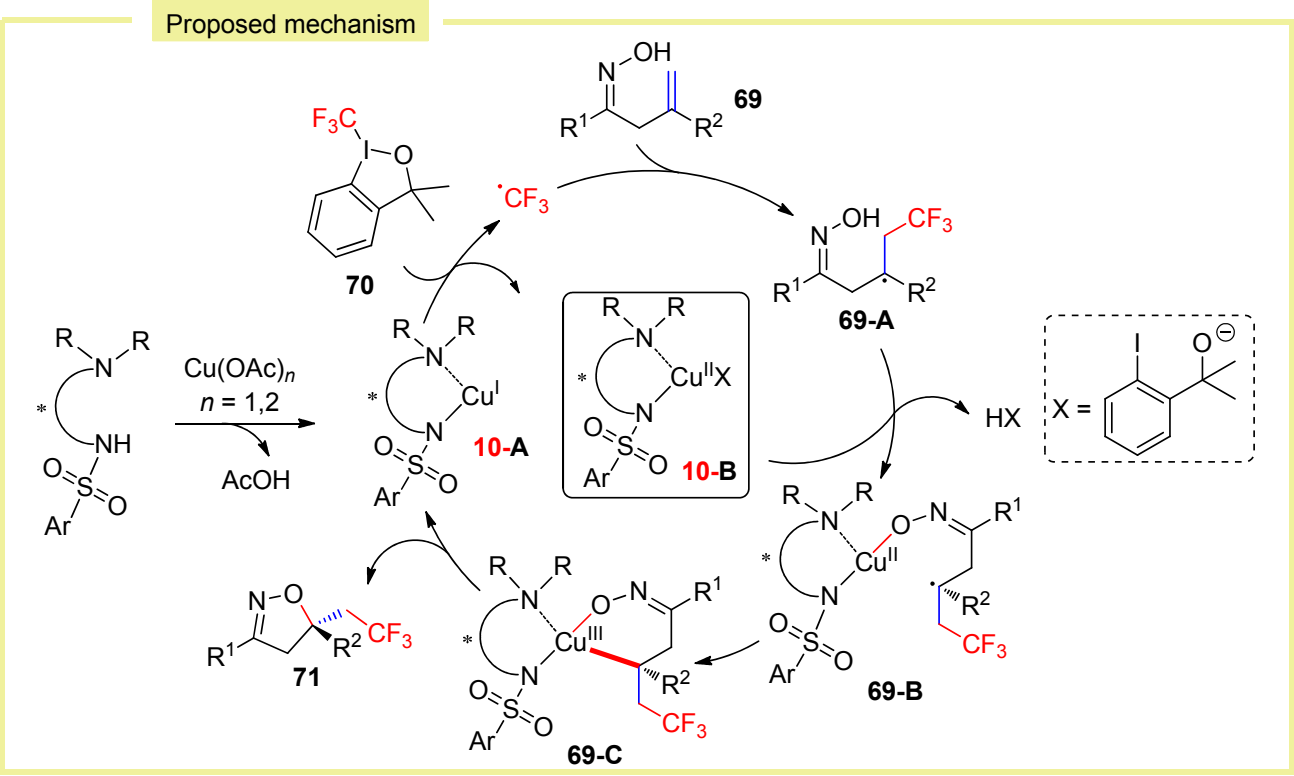

图式 25 铜/金鸡纳碱磺酰胺催化烯基肟的不对称氧三氟甲基化反应

Scheme 25 Asymmetric oxytrifluoromethylation of alkenyl oximes catalyzed by copper/cinchona alkaloid-based sulfonamide 


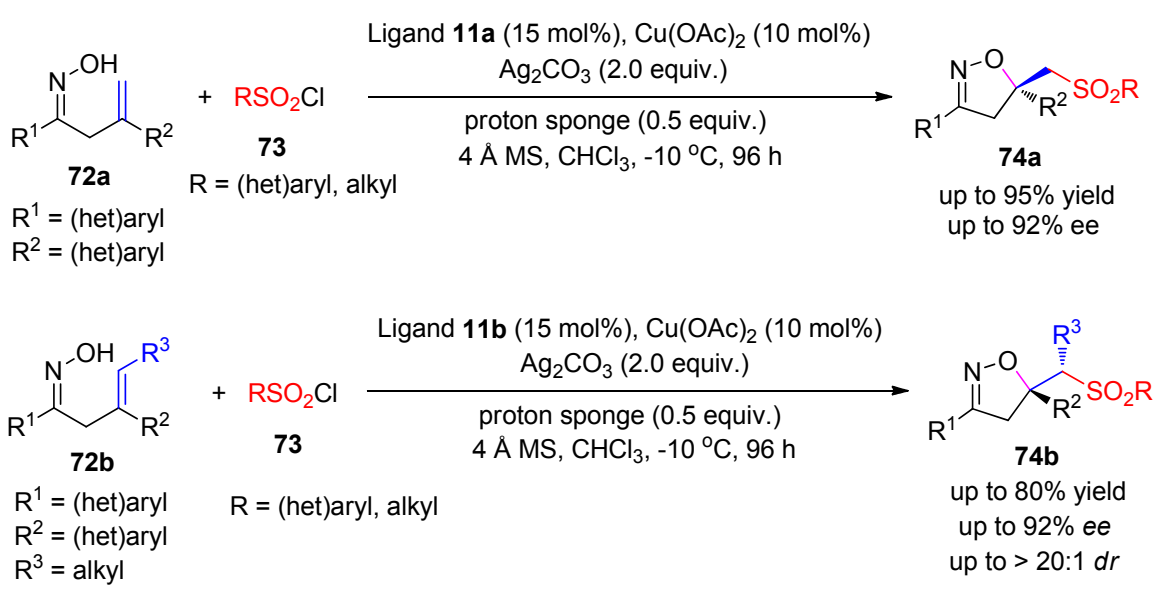

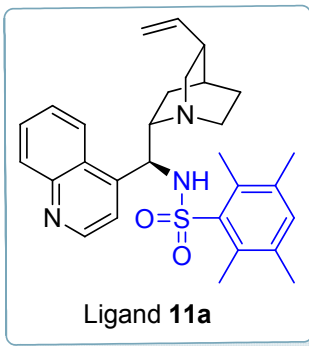

$1=$ (het)aryl $\mathrm{R}^{2}=$ (het)ary $\mathrm{R}^{3}=$ alkyl

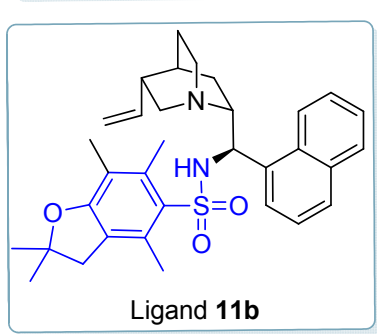

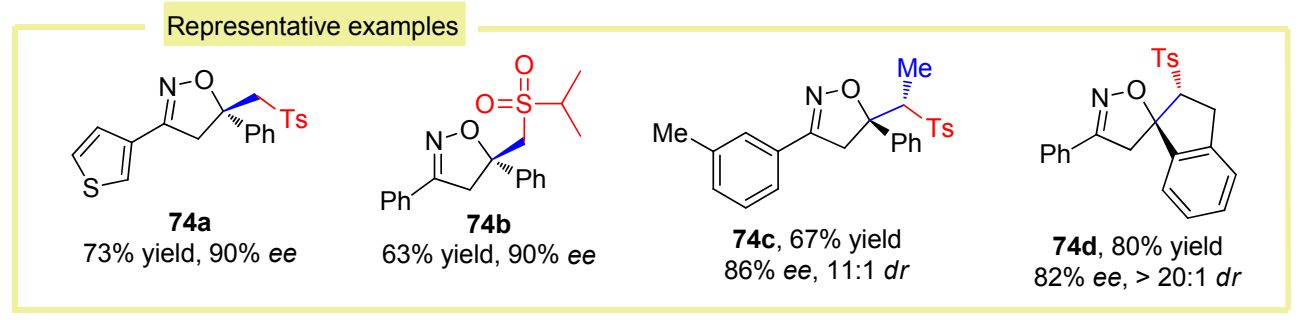

图式 26 非对映选择性和对映选择性的 $\beta, \gamma$-不饱和酮肜的自由基氧磺酰化反应

Scheme 26 Diastereo- and enantio-selective radical oxysulfonylation reaction of $\beta, \gamma$-unsaturated ketoximes

动力学控制下，烷基自由基中间体 72-B 优先进行反应， 通过分子内的自由基取代反应，立体选择性地形成 $\mathrm{C}$ $\mathrm{O}$ 键, 产生络合 72-C, 该络合物最终解离生成产物 74 和 $\mathrm{Cu}(\mathrm{I})$ 络合物 11-A. 这一策略的成功实施将为自由基 介导的、非末端烯烃的不对称双官能化反应的对映选择 性及非对映选择性的精确立体控制打开一扇新的大门.

2019 年, 何炜课题组 ${ }^{[44]}$ 设计了一类新型金鸡纳碱 衍生的噁唑啉配体 12, 实现了钯催化含氮二烯芳香化 合物 75 分子内的不对称 Aza-Wacker 氧化串联环化反应, 最终以良好的收率, 优异的对映选择性和非对映选择性 得到目标产物 76 (Scheme 28). 值得一提的是, $\mathrm{HNTf}_{2}$ 对 反应的立体选择性有着十分重要的影响, 可能的原因 是: $\mathrm{HNTf}_{2}$ 可以稳定二价钯离子. 该反应条件温和, 操 作简单, 而绿色氧化剂氧气的使用使得该反应更加经济 环保.

\section{$3.2 .2 \mathrm{~N}, \mathrm{O} / \mathrm{S}$ 配位}

2009 年, Skarzewski 课题组 ${ }^{[45]}$ 开发了金鸡纳碱衍生 的手性硫醇配体 13, 实现了苯甲醛 77 与硝基甲烷 7 的 不对称 Henry 反应(Scheme 29). 对于可能的作用模型, 作者认为手性硫醇配体占据赤道平面两个配位点. 与此 同时，金属铜作为路易斯酸活化底物醛. 硝基甲烷则在 轴向位置与铜配位, 使得亲核试剂从空间位阻更小的 $R e$ 面进攻醛羰基从而得到 $S$ 构型的手性产物.
2011 年, 何炜课题组 ${ }^{[46]}$ 在此基础上开发了金鸡纳 碱衍生的席夫碱手性氮氧配体 14 , 并成功应用到铜催 化的不对称 Henry 反应中，完成了对一系列邻硝基仲醇 68 的高效合成(Scheme 30). 对于可能的作用模式，作者 认为两分子手性配体占据金属铜四个配位点，同时金属 铜作为路易斯酸活化底物, 而由于醛 $\mathrm{R}^{1}$ 基团与喹啉环 空间上的排斥作用，从而使得亲核试剂将从空间位阻更 小的 $R e$-面进攻醛羰基.

\subsubsection{N,P 配位}

2008 年, 张生勇课题组 ${ }^{[47]}$ 从商业可得的光学纯 1,2二芳基乙二醇和金鸡纳碱为初始原料，经过两步一锅简 单的转化，就能得到金鸡纳碱衍生的手性氮磷配体 $\mathbf{1 5}$, 这也是该类配体的首次合成(Scheme 31). 作者也成功 将该配体应用于钯催化的不对称烯丙基烷基化反应. 该 手性氮磷配体的合成，是对钯催化烯丙基反应可选择配 体的补充.

2011 年, Dixon 课题组 ${ }^{[48]}$ 设计了一类金鸡纳碱衍生 的新型手性膦胺配体 16. 在零下二十度, $\mathrm{Ag}_{2} \mathrm{O}$ 作催化 剂, AcOEt 作溶剂的条件下, 成功实现了异氰酸酯 82 与 醛 36 的不对称 Aldol 反应(Scheme 32). 该反应适用于芳 基醛和具有支链的脂肪醛，能够以优异的收率、对映选 择性和非对映选择构筑一系列具有重要生物活性的噁 唑啉骨架. 但是对于直链脂肪醛却不能兼容. 同时, 降 


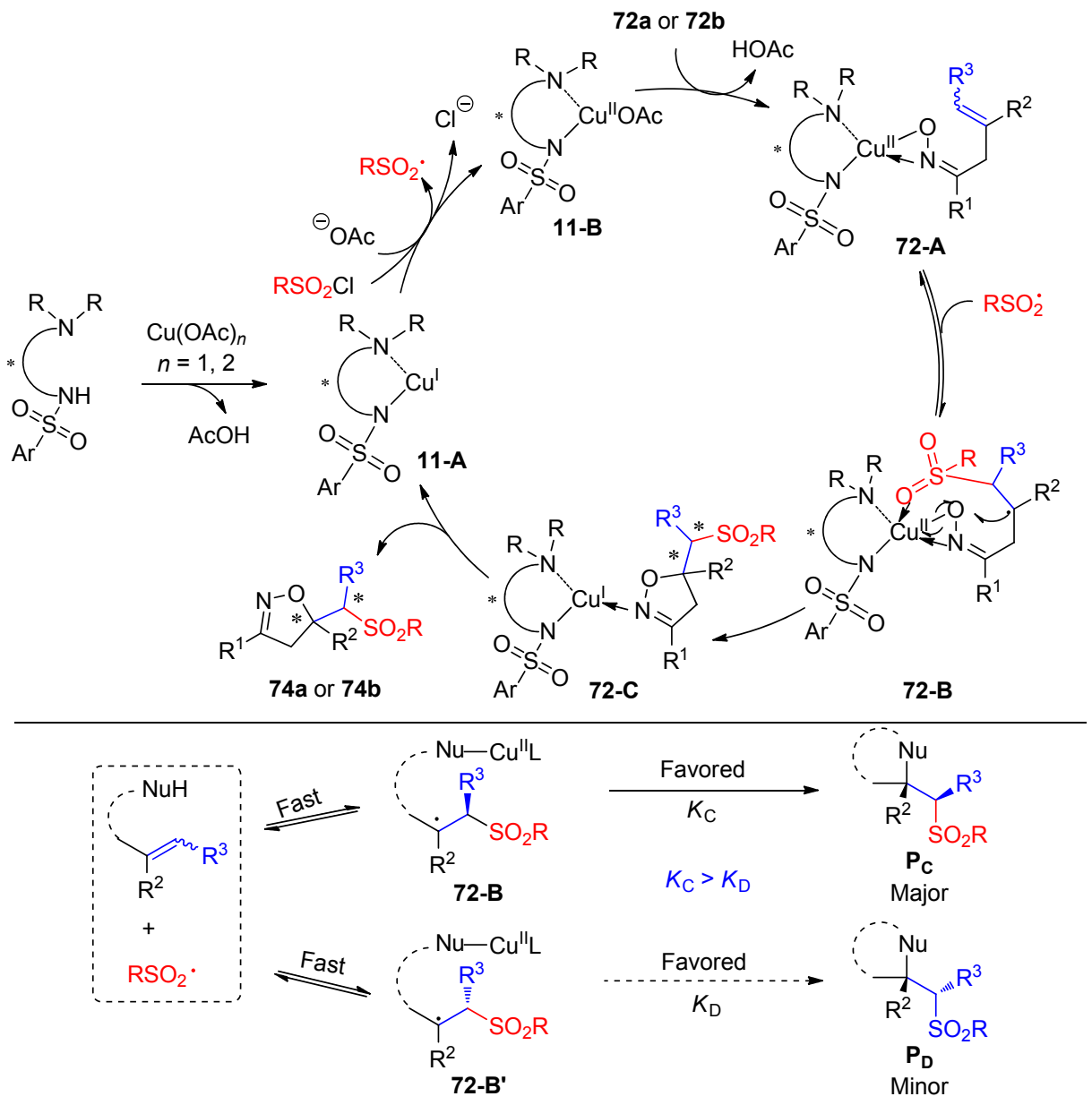

图式 27 可能的机理及 Curtin-Hammett 原理

Figure 27 Plausible reaction mechanism and Curtin-Hammett principle

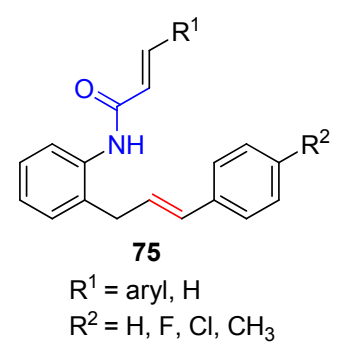

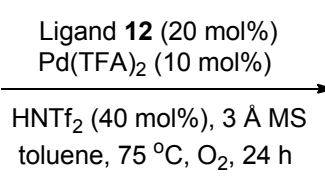

0.5 equiv, 2,6 -lutidine

$\mathrm{R}^{2}=\mathrm{H}, \mathrm{F}, \mathrm{Cl}, \mathrm{CH}_{3}$

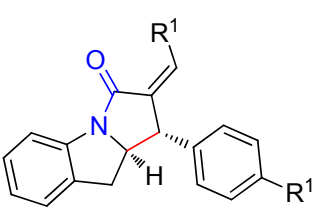

76

up to $83 \%$ yield up to $97 \%$ ee, $>20: 1 d r$

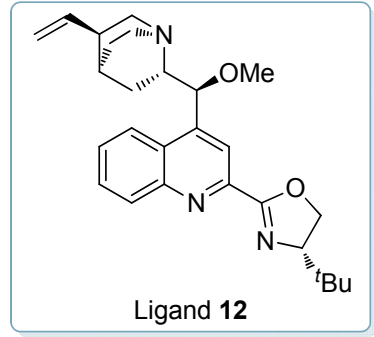

Ligand 12

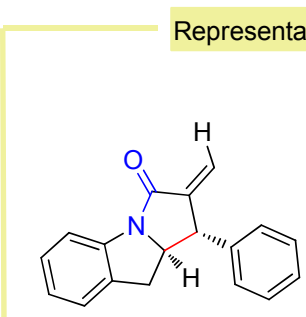

$76 a$

$63 \%$ yield, $97 \%$ ee

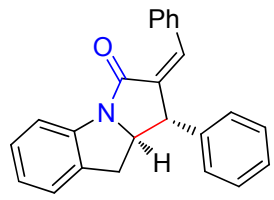

$76 \mathrm{~b}$ $67 \%$ yield, $90 \%$ ee

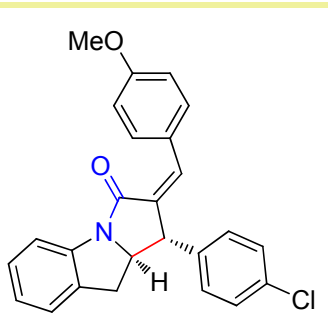

$76 \mathrm{c}$

$68 \%$ yield, $90 \%$ ee

图式 28 钯/金鸡纳碱噁唑啉络合物催化分子内的 Aza-Wacker 氧化串联环化反应

Scheme 28 Enantioselective intramolecular aza-Wacker oxidation cyclization reaction catalyzed by palladium/cinchona alkaloid-derived oxazoline complex 


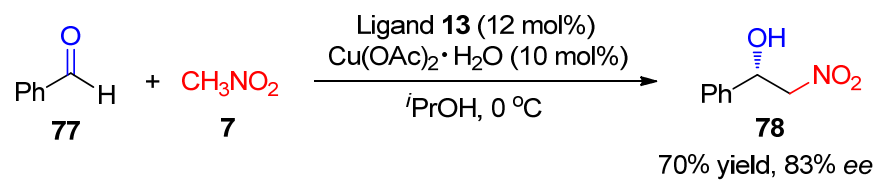
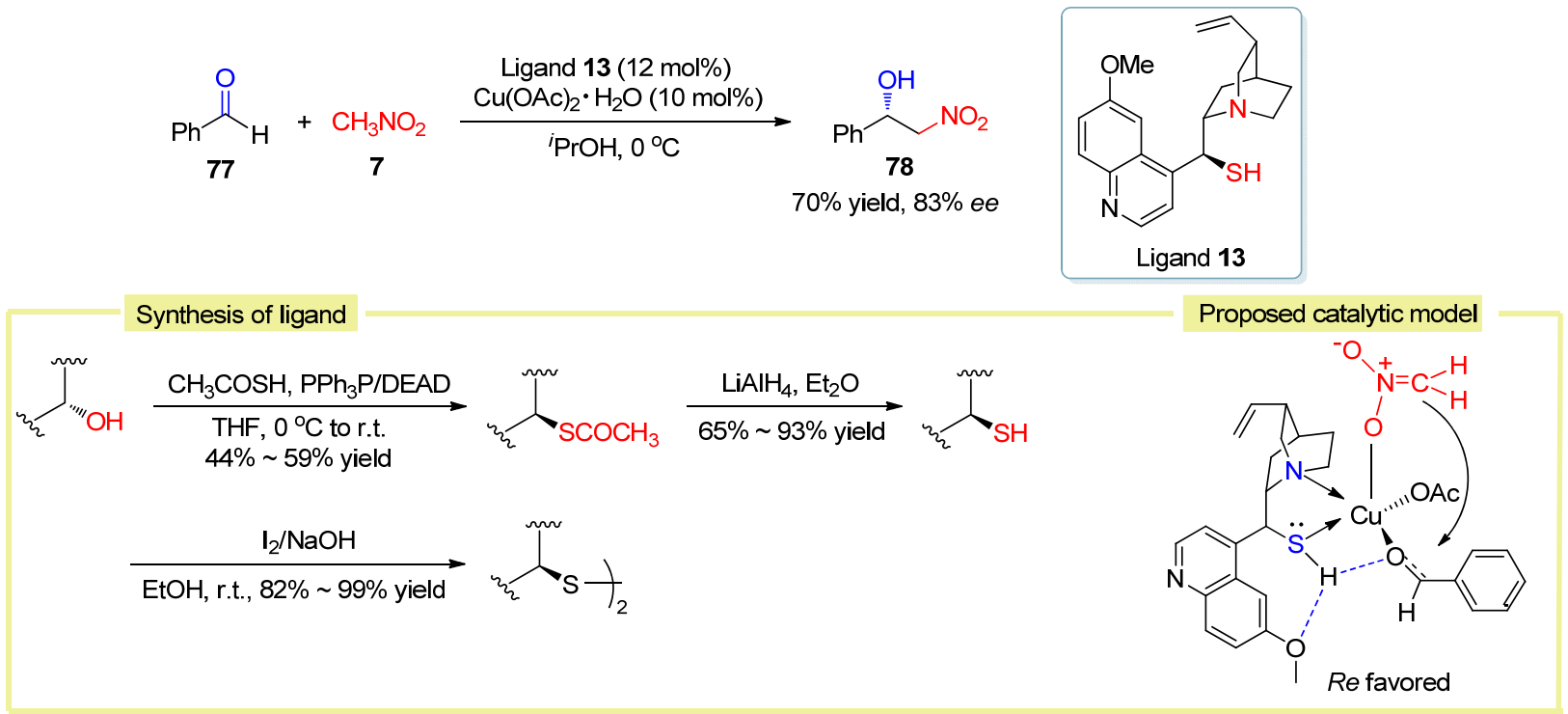

图式 29 铜催化的不对称 Henry 反应

Scheme 29 Asymmetric Henry reaction catalyzed by copper(II) complex

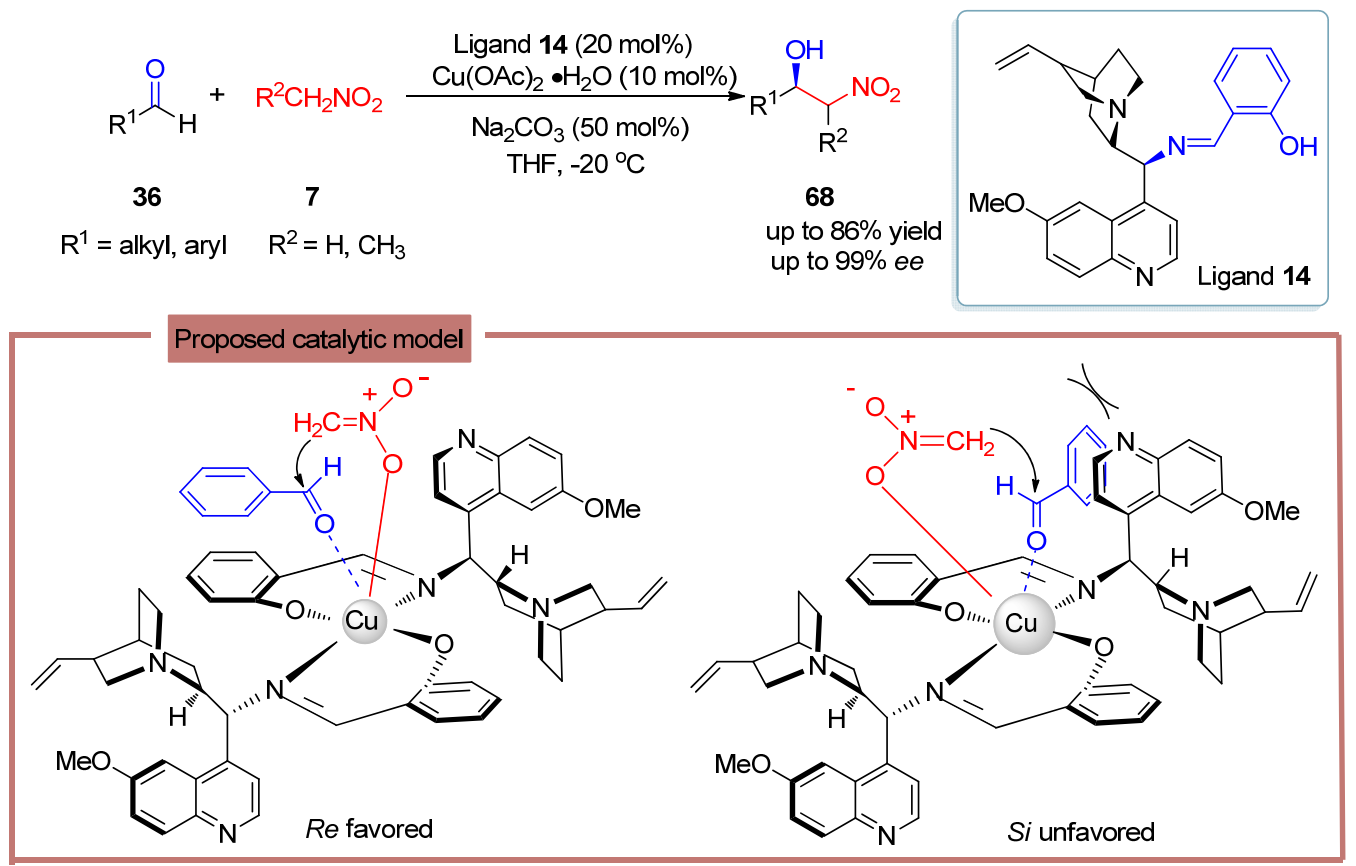

图式 30 铜/金鸡纳碱席夫碱络合物催化的不对称 Henry 反应

Scheme 30 Asymmetric Henry reaction catalyzed by copper(II)/cinchona alkaloid-derived Schiff base
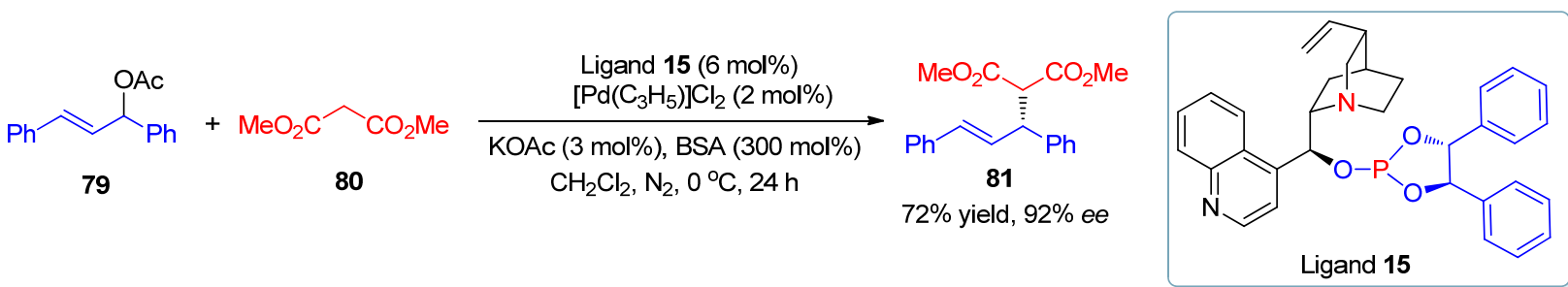

图式 31 钯/金鸡纳碱衍生 $\mathrm{P}, \mathrm{N}$ 配体催化不对称烯丙基烷基化反应

Scheme 31 Asymmetric allylic alkylation catalyzed by palladium/cinchona alkaloid-derived P,N ligand 
低此反应催化剂的用量对反应并无较大影响. 对于可能 的作用模式, 作者认为手性膦胺配体与一价银盐形成的 复合物可作为布朗斯特碱/路易斯酸双功能催化剂, 从 而实现对该反应的高效催化和手性控制. Dixon 课题 组 ${ }^{[49-51]}$ 还把该催化体系分别成功应用于了 $\alpha$-取代异氧 酸酯与酮的 Aldol加成/环化反应以及酮亚胺的对映选择 性 Mannich 加成/环化反应，合成了一系列多官能化的 咪唑啉产物.
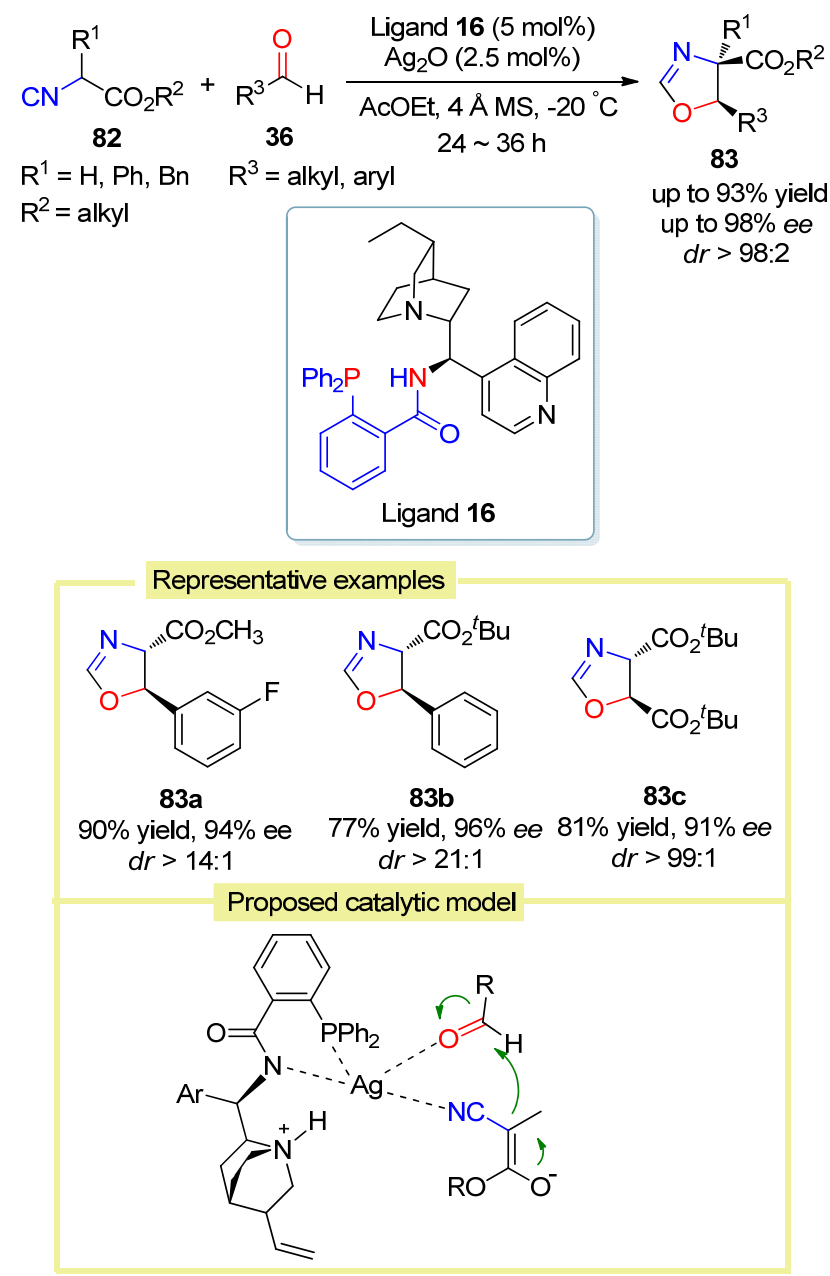

图式 32 银催化的异氰乙酸乙酯不对称 Aldol 反应/环化 Scheme 32 Asymmetric aldol reaction/cyclization of isocyanoacetates catalyzed by silver(I)/amino-phosphine

2017 年, Dixon 和 Paton 等 ${ }^{[52]}$ 基于烯胺催化与金属 协同催化策略, 利用相似的手性膦胺配体 17a 实现了 4炔丙基胺环已酮 84 的环异构化反应(Scheme 33). 在该 反应中，首先有机胺催化剂和羰基原位生成高反应活性 的烯胺中间体，随后与被银复合物活化的端炔发生分子 内的亲核加成反应. 基于之前的研究成果，作者通过 DFT 计算进一步验证了可能的作用模式: 手性膦胺配体 中氮磷原子与银配位; 另一方面, 金属银作为 $\pi$ 酸活化 端炔. 同时, 作者也发现酰胺与磺酰胺之间存在 $\mathrm{N}$ $\mathrm{H} \cdots \mathrm{O}$ 的氢键作用. 反应具有良好的官能团兼容性和底
物适用范围，原子经济性高. 产物 85 作为合成药物吗啡 的关键中间体，因此，该策略在有机合成中有较大的应 用价值.
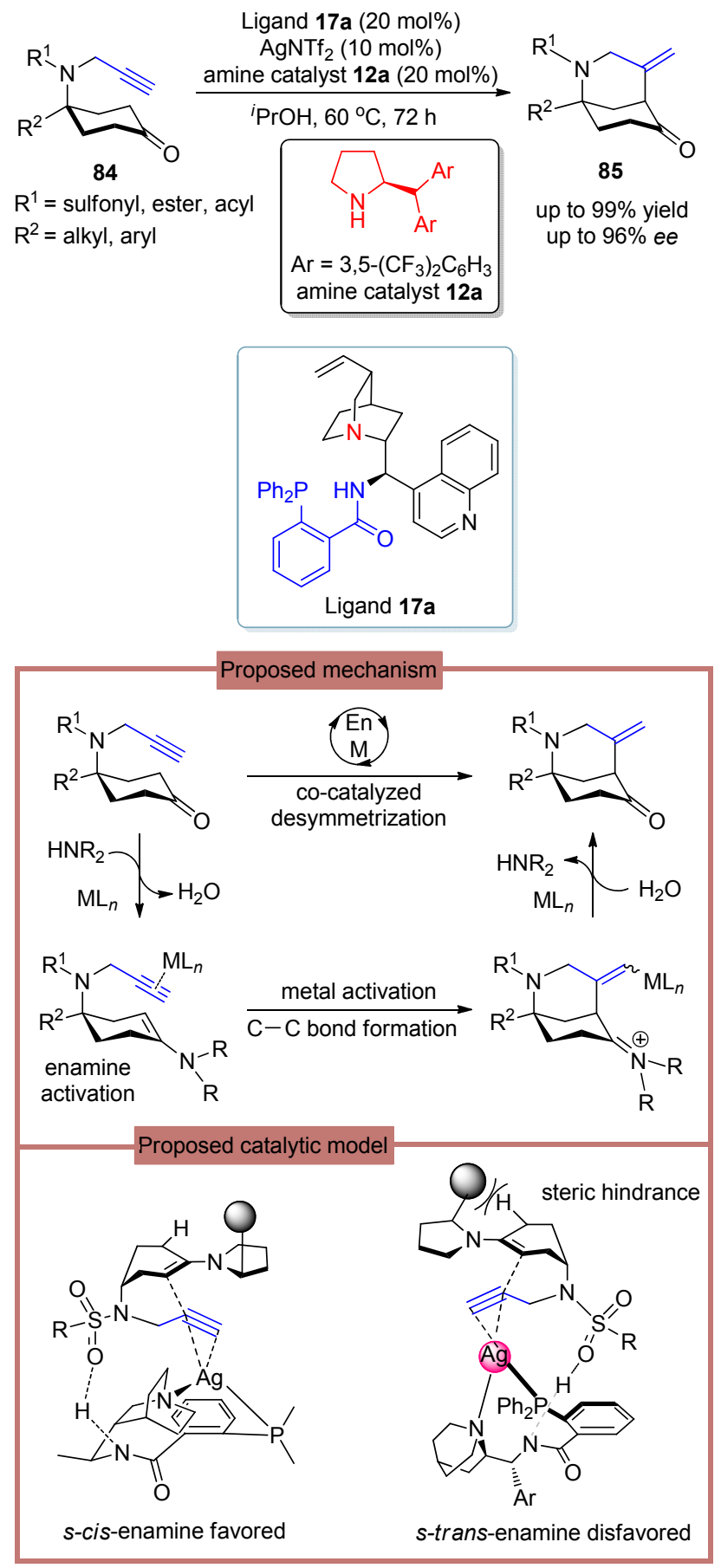

图式 33 银与胺共催化烷基环己酮的去对称化环异构化反应 Scheme 33 Desymmetrizing cycloisomerization of alkyl cyclohexanones catalyzed by silver and amine

作者认为催化体系中两个手性配体之间存在着明 显的匹配和不匹配效应，如 Scheme 34 所示：当使用手 性匹配的 $R$ 构型的吡咯烷 ent-12a 和金鸡纳碱衍生的胺 基膦配体 17b 时，可以高效、高对映选择性的获得产物 


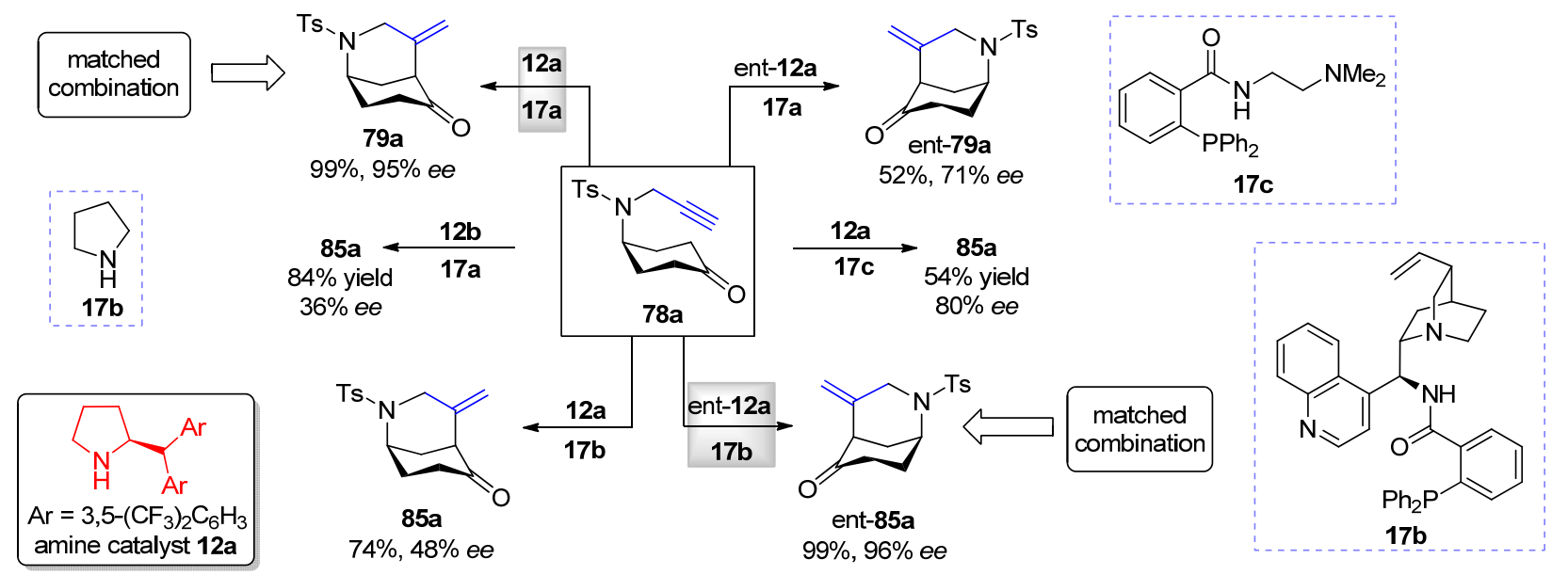

图式 34 手性匹配/不匹配效应

Scheme 34 Effects of chiral match/mismatch

吗啡 85a 的对映体 ent-85a (Scheme 34, 左上和右下比 较). 相反, 当使用手性不匹配的配体组合 $\mathbf{1 2 a} / \mathbf{1 7 b}$ 或者 ent-12a/17a 时 (Scheme 34, 右上和左下比较), 反应的效 率和对映选择性均大幅降低. 另外, 当作者使用非手性 的吡咯烷 $12 \mathrm{~b}$ 和金鸡纳碱衍生的手性胺基膦配体 $17 \mathrm{a}$ 时, 反应仅能以 $36 \%$ 的对映选择性得到目标产物 85a; 而当 使用非手性的配体 $17 \mathrm{c}$ 和手性配体 12a 时, 则能够以 $80 \%$ 的对映体过量得到产物 85a. 此结果表明, 吡咯烷 在此反应的对映选择性控制中发挥着主要作用.

具有轴手性的联芳基骨架, 尤其是芳基-杂芳基骨 架, 存在于许多重要的天然产物和药物中, 也是许多配 体和催化剂的关键结构. 2019 年, 祝介平等 ${ }^{[33]}$ 开发了一 类高效的氧化银和手性膦胺配体 18 , 催化 $\alpha$-异氧基乙 酸乙酯 82 与 $\beta$-芳基- $\alpha, \beta$-炔基酮 86 的不对称杂环反应 (Scheme 35). 该反应以高收率和高对映选择性实现了 3芳基吡咯类化合物 87 的轴手性构建. 作者认为, 在此反 应中, 配体上的酰胺氮、膦、炔酮物种上的羰基氧和异 氭化物的碳原子和催化剂的银进行配位, 从而确定了两 种反应物的空间位置. 配体上质子化的奎宁环和酮氧之 间的氢键作用, 可以进一步改善络合物的立体化学环 境, 最终形成过渡结构 86-A. 由于空间位阻的原因, 烯 醇化合物将从炔烃的背面进攻，立体选择性地得到中间 体 86-B. 随后, 发生分子内环化得到中间体 86-C. 中间 体 86-C 发生质子化产生中间体 86-D. 最后经过 1,5-氢 转移得到具有轴手性的 3-芳基吡咯类化合物 87. 作者 通过对底物电性的调控, 完美地避免了亲核试剂对炔酮 的 1,2-加成反应. 此外, 反应具有良好的官能团耐受性 和底物适应性，具有实际的应用价值.

\section{3 三齿配位}

2007 年, Lin 课题组 ${ }^{[54]}$ 设计了金鸡纳碱衍生的席夫
碱三齿配体 19, 并将其成功地应用到有机金属试剂二 乙基锌与芳香醛 88 的亲核加成反应中，高效地构建了 一系列 1-芳基丙醇化合物 89 (Scheme 36). 对于可能的 作用模式，作者认为手性配体作为三齿配体与金属锌形 成复合物，与此同时，奎宁环三级胺作为路易斯碱，达 到了路易斯酸一路易斯碱双功能活化的目的。该反应条 件温和, 能以令人满意的收率和对映选择性得到目标化 合物.

2012 年, 张生勇和何炜课题组 ${ }^{[55]}$ 将其团队开发的 金鸡纳碱衍生的手性席夫碱配体 14 进行修饰后得到配 体 20, 并将其成功应用到醛 36 与硝基甲烷 7 的不对称 Henry 反应中(Scheme 37). 相比之前的工作, 催化中心 铜的空间和电子效应由于叔丁基的加入得到了调控，反 应的收率及对映选择性明显提升，同时手性配体和催化 剂的用量也均降至 $5 \mathrm{~mol} \%$. 此外, 通过单晶衍射和 NMR 数据, 他们给出了催化模式.

Sonogashira 偶联反应作为构建碳一碳键的一种经典 方法, 受到了化学家们的广泛关注. 然而, 不对称的 Sonogashira 偶联反应, 尤其是对 $\mathrm{C}\left(\mathrm{sp}^{3}\right)-\mathrm{C}(\mathrm{sp})$ 碳-碳键 的不对称构建在很大程度上仍未得到开发. 2019 年, 刘 心元课题组 ${ }^{[56]}$ 报道了利用 $\mathrm{Cu}(\mathrm{I})$ /金鸡纳生物碱的 P,N-配 体催化体系，基于自由基过程实现了卤代烃 91 与炔烃 90 的不对称 Sonogashira $\mathrm{C}\left(\mathrm{sp}^{3}\right)-\mathrm{C}(\mathrm{sp})$ 偶联反应(Scheme 38). 该反应操作简单，反应条件温和，对于一系列末端 的炔烃和消旋的烷基卤化物具有很好的普适性 $(>120$ 个实例). 此外，该方法也能很好地使用工业原料乙炔 气体作为底物, 从而高度单一地合成有价值的手性末端 炔烃类化合物 $(92 \mathrm{a}, 92 \mathrm{~b})$, 所获得手性端炔类化合物可 以进一步发生后续反应，从而以高收率和对映选择性产 生环加成产物 92c. 该手性端炔类化合物可以进行第二 次不对称的 Sonogashira 偶联反应, 以高非对映选择性 


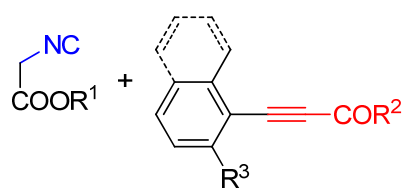

82 86 $\mathrm{R}^{1}=$ alkyl; $\mathrm{R}^{2}=$ aryl; $\mathrm{R}^{3}=$ alkyl, halogen

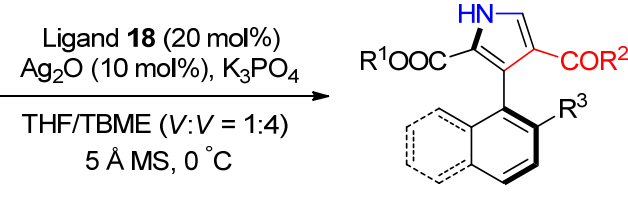

87

up to $98 \%$ yield up to $96 \%$ ee

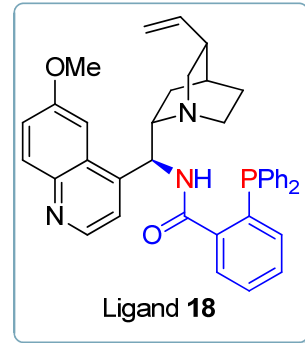

Proposed catalytic model

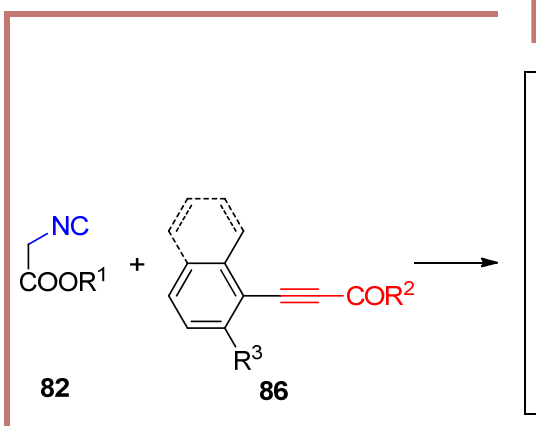

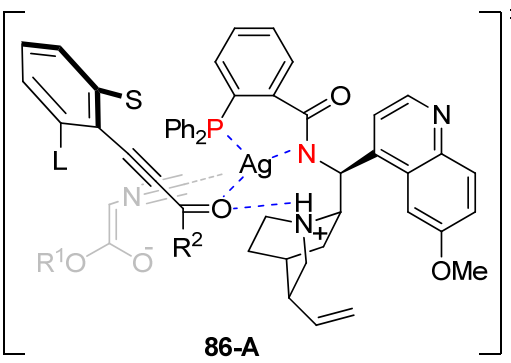

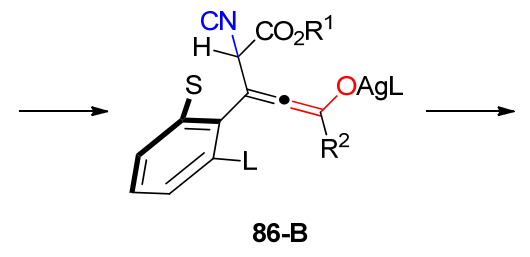<smiles>[R20]C(=O)C1=C(c2c(S)cccc2I)C(C([R])=O)N=C1[Ge]</smiles>

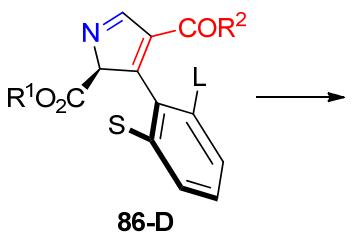

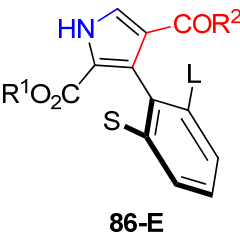

图式 35 银催化合成轴手性 3-芳基吡咯类化合物

Scheme 35 Synthesis of axially chiral 3-arylpyrroles catalyzed by silver
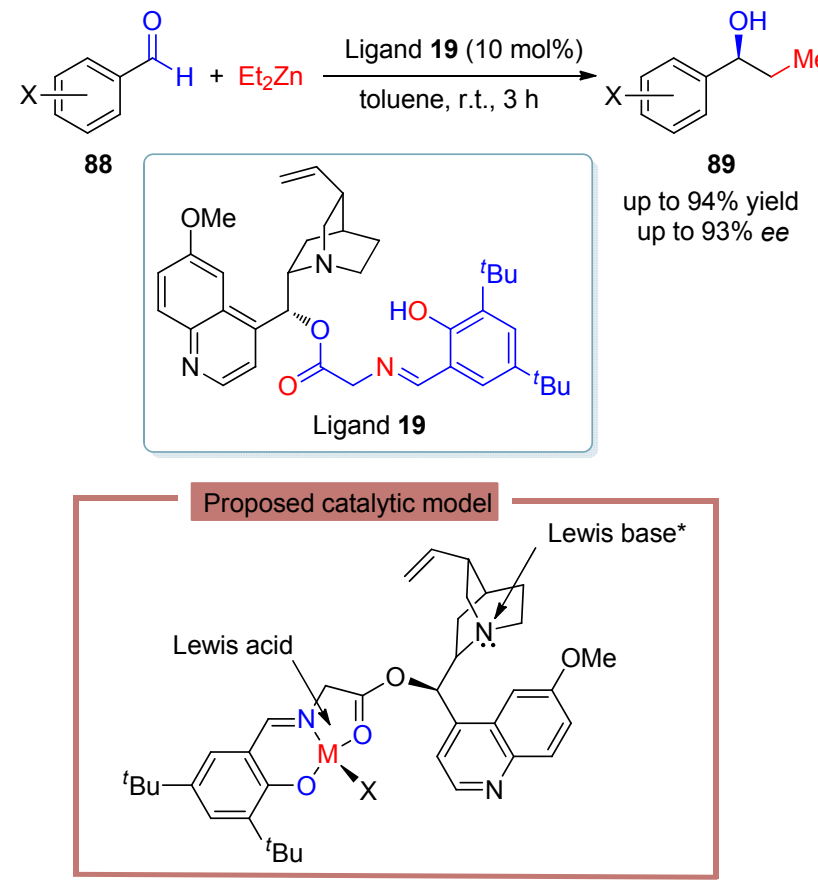

图式 36 席夫碱-锌(II)复合物催化二乙基锌与醛的不对称加 成反应

Scheme 36 Asymmetric addition of diethylzinc to aldehydes catalyzed by Schiff base-Zn(II) complex
提供产物 92d. 自由基前体片段不仅仅局限于外消旋的 $\alpha$-芳基和杂芳基取代的烷基卤化物，烯丙基和 $\alpha$-炔基/ 氧基/酰胺类烷基溴化物也能很好地适用于该转化(92e, 92f，92g，92h). 更重要的是，此方法能够兼容具有生物 活性和功能分子的核心骨架，为药物和天然产物的合成 和后期修饰提供了一种可行的方法. 通过自由基捕获和 自由基钟实验，作者认为该反应体系涉及茮基自由基过 程.

2020 年, 刘心元课题组 ${ }^{[57]}$ 利用消旋的 $N$-差基邻苯 二甲酰亚胺类酯 93 作为烷基自由基前体，在光引发铜 催化的条件下实现了其与端炔 94 的不对称自由基脱羧 $\mathrm{C}\left(\mathrm{sp}^{3}\right)-\mathrm{C}(\mathrm{sp})$ 偶联反应(Scheme 39). 在该反应中, 端炔/ 铜(I)/金鸡纳碱衍生的手性 N,N,P-配体三组分在碱性条 件下原位生成炔铜(I)复合物，该复合物可吸收蓝光到达 激发态而充当具有强还原能力的光催化剂，从而将底物 $N$-羟基邻苯二甲酰亚胺类酯还原生成烷基自由基物种 以及释放出一分子二氧化碳. 该反应展示出优异的底物 适用范围和官能团兼容性，以中等到较好的产率和优秀 的立体选择性得到相应的偶联产物. 该工作也进一步拓 展了该类催化体系的适用性, 弥补了以往的方法中较难 适用于烷基卤代物以及不稳定前体等不足. 

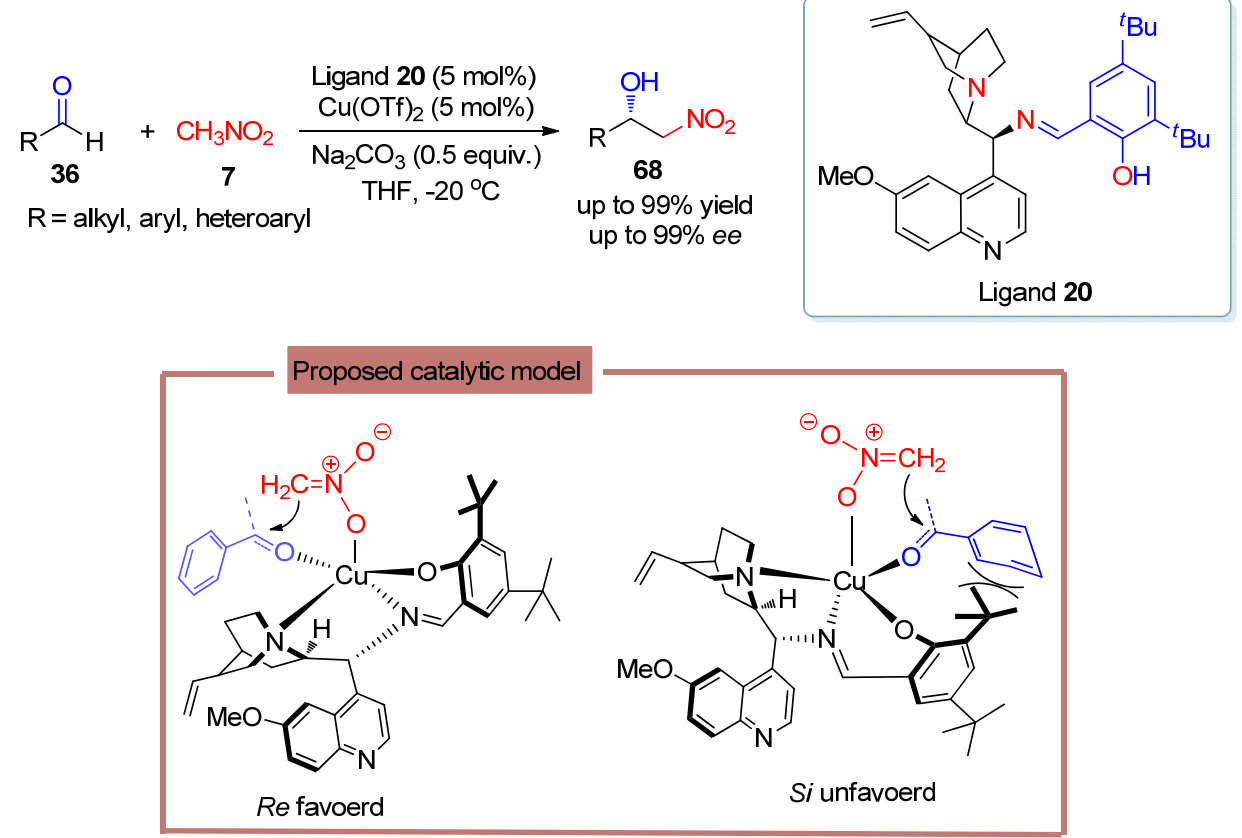

图式 37 铜/金鸡纳碱席夫碱催化的不对称的 Henry 反应

Scheme 37 Asymmetric Henry reaction catalyzed by copper(II)/cinchona alkaloid-derived Schiff base

2019 年, 刘心元课题组 ${ }^{[58]}$ 基于之前的工作, 利用 铜/金鸡纳生物碱的 N,N,P-配体催化体系, 实现了远端 未活化的 $\mathrm{C}\left(\mathrm{sp}^{3}\right)-\mathrm{H}$ 键和末端炔烃的自由基不对称氧化 $\mathrm{C}\left(\mathrm{sp}^{3}\right)$ - $\mathrm{C}(\mathrm{sp})$ 交叉偶联反应, 具有高度的区域、化学和 对映选择性(Scheme 40). 使用 $N$-氟代酰胺作为温和的 酰胺氮自由基前体和氧化剂, 产生氮自由基以后通过分 子内的 1,5-或者 1,6-氢迁移过程, 可以将远端未活化的 $\mathrm{C}\left(\mathrm{sp}^{3}\right)-\mathrm{H}$ 键转化为相应的烷基自由基, 同时也有效避 免了末端炔烃的自身的 Glaser 偶联反应. 该反应适用于 一系列取代的芳基和杂芳基炔类化合物. 对于(杂)芐基 和炔丙基的 $\mathrm{C}\left(\mathrm{sp}^{3}\right)-\mathrm{H}$ 键也能够有效的兼容. 基于机理 探究实验和先前的文献报道, 作者提出了可能的反应机 理: 首先, 在碱的存在下, $\mathrm{Cu}(\mathrm{I})$ 与手性配体和末端炔烃 发生反应, 产生相应的络合物 97-B. 随后, 络合物 97-B 与底物 96 发生单电子转移过程, 形成 $\mathrm{Cu}(\mathrm{II})$ 络合物 97-C 和酰胺氮自由基物种 97-A. 接着, 酰胺氮自由基物种 96-A 通过分子内的 1,5 或者 1,6 氢迁移产生烷基自由基 中间体 96-B. 然后, 烷基自由基中间体 96-B 被 $\mathrm{Cu}(\mathrm{II})$ 络合物 97-C 捕获, 产生 $\mathrm{Cu}(\mathrm{III})$ 络合物 97-D. 最后, 通过 还原消除生成目标产物 98 和重新生成 $\mathrm{Cu}(\mathrm{I})$ 络合物 97-A.

2020 年, 刘心元课题组 ${ }^{[59]}$ 利用其团队开发的金鸡 纳碱衍生的 N,N,P-多齿手性配体 21, 在铜催化的条件 下, 从易于获得的烷基卤化物和末端炔烃出发, 实现了 烯烃 100 分子间不对称自由基 1,2-烷基炔基化反应, 能
够以优异的收率和对映选择性高效地制备了一系列手 性炔化合物 102 (Scheme 41). 该反应底物范围广和优异 官能团兼容性，适用于各种(杂)芳基、炔基和酰胺取代 的烯烃，(杂)芳基、烷基和甲硅烷基取代的炔烃，以及各 种取代的一级、二级和三级烷基自由基前体. 重要的是 该反应为烯烃的不对称 1,2-双官能化提供了一种可行的 策略. 基于控制实验、EPR 光谱实验、NMR 实验等其 它机理研究, 作者提出了如下的反应过渡态. 底物中相 对较大的(杂)芳基与配体中的 P-3,5-二叔丁基苯基之间 由于空间位阻导致 $S i$-Ts 不利, 从而产生绝对构型为 $R$ 的产物。该策略与直接通过 $\mathrm{C}\left(\mathrm{sp}^{2} / \mathrm{sp}^{3}\right)$ 试剂实现烯烃的 双官能化反应形成很好的互补, 具有较大的应用价值.

\section{4 总结与展望}

综上所述，因其优势的手性骨架特点和丰富的可修 饰潜力, 金鸡纳生物碱及其衍生物作为有机催化剂在不 对称合成中已有了十分广泛的应用, 但其催化活化模式 较为单一, 对反应底物适用范围有一定的局限性. 而将 其作为手性配体参与金属催化的不对称合成发展虽然 起步较早, 但发展却相对缓慢, 反应类型受限, 仍然有 非常大的发展空间. 相信通过科研工作者的努力, 将可 以开发出更加丰富多样的金鸡纳碱衍生的催化剂及手 性配体, 进一步将其应用到各式各样的反应类型中, 进 一步推动不对称合成的发展. 


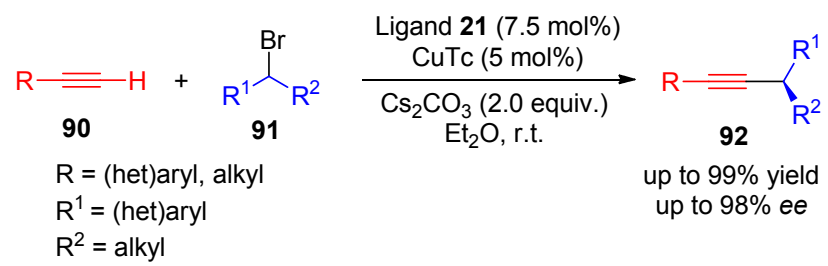

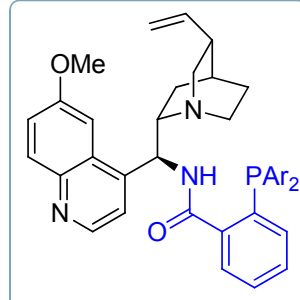

$\mathrm{Ar}=3,5-{ }^{\mathrm{t}} \mathrm{Bu}_{2} \mathrm{C}_{6} \mathrm{H}_{3}$

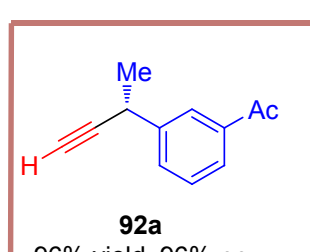

$96 \%$ yield, $96 \%$ ee

\section{Representative examples}

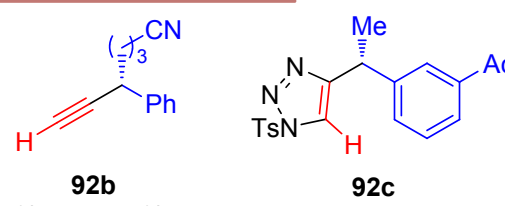

$77 \%$ yield, $95 \%$ ee

$81 \%$ yield, $95 \%$ ee

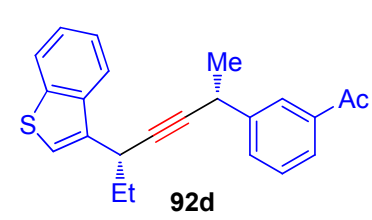

$49 \%$ yield, $95 \%$ ee

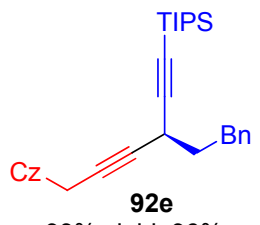

$93 \%$ yield, $96 \%$ ee

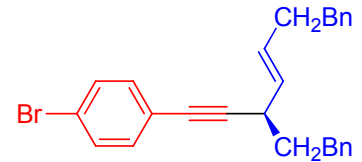

$92 \mathrm{f}$

$97 \%$ yield, $76 \%$ ee $E / Z=4: 1$<smiles>N#CC(Cl)C#CCCl</smiles>

92g

$61 \%$ yield, $77 \%$ ee<smiles>CCC(C#CCCl)C(=O)N(C)c1ccccc1</smiles>

92h $92 \%$ yield, $86 \%$ ee

Synthetic applications in medicinal chemistry<smiles>CC#CC(CC(=O)O)c1ccc(OCc2cccc(-c3ccc(C(F)(F)F)cc3)c2)cc1</smiles>

92i

AMG 837, a GPR40 agonist for type 2 diabetes 7 steps, $10 \%$ overall yield, $83 \%$ ee

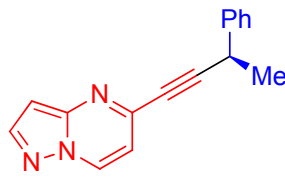

92j

a mGluR modulator for neurological disorders 3 steps, $69 \%$ yield, $93 \%$ ee

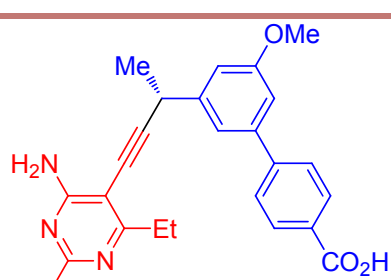

$\mathrm{H}_{2} \mathrm{~N}$

92k

UCP1172, DHFR inhibitor for bacterial infection 5 longest, linear steps $27 \%$ overall yield, $92 \%$ ee

图式 38 铜催化的不对称 Sonogashira 偶联反应

Scheme 38 Asymmetric Sonogashira coupling catalyzed by copper/cinchona alkaloid-based P,N-ligand

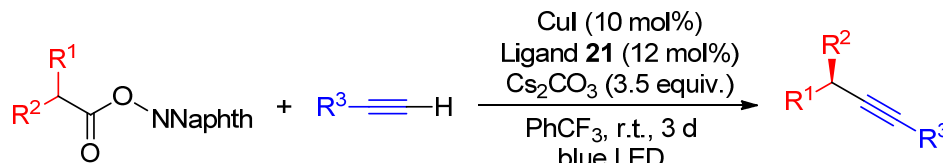

93

94

$\mathrm{R}^{1}=$ alkyl; $\mathrm{R}^{2}$ = (het)aryl, alkenyl, amide $\mathrm{R}^{3}=$ (het)aryl, alkyl, alkenyl, silyl alkynes
95

up to $81 \%$ yield up to $99 \%$ ee

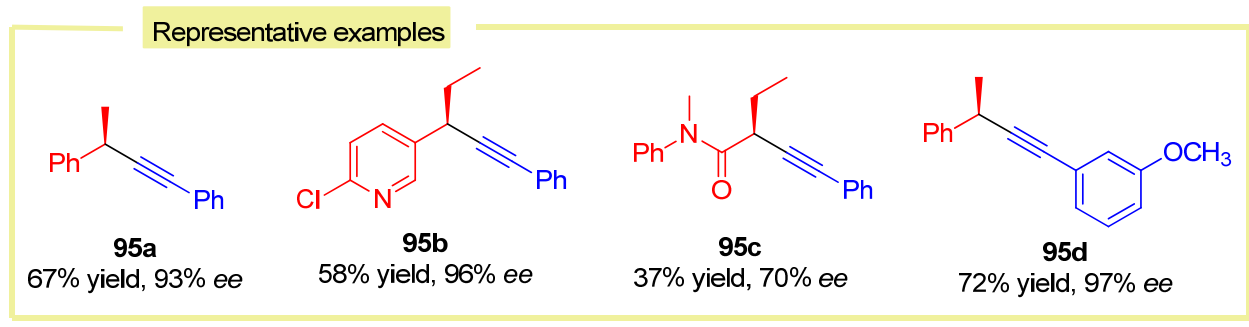

图式 39 光驱动铜催化不对称自由基脱羧偶联反应

Scheme 39 Photoinduced copper-catalyzed asymmetric radical decarboxylation coupling reaction 


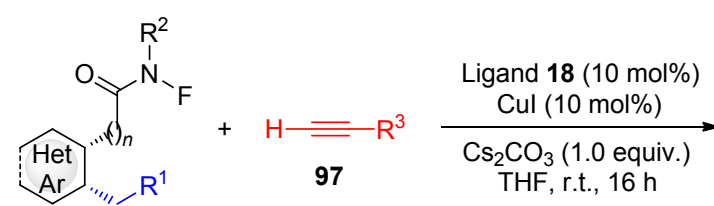

96

$n=1,2 ; \mathrm{R}^{1} / \mathrm{R}^{2}=$ alkyl; $\mathrm{R}^{3}=$ alkyl, (het)aryl

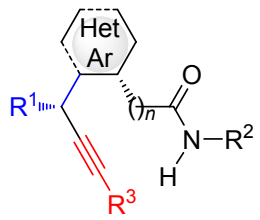

98

up to $98 \%$ yield up to $97 \%$ ee

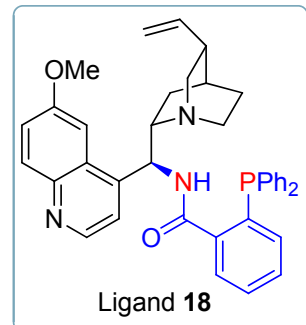

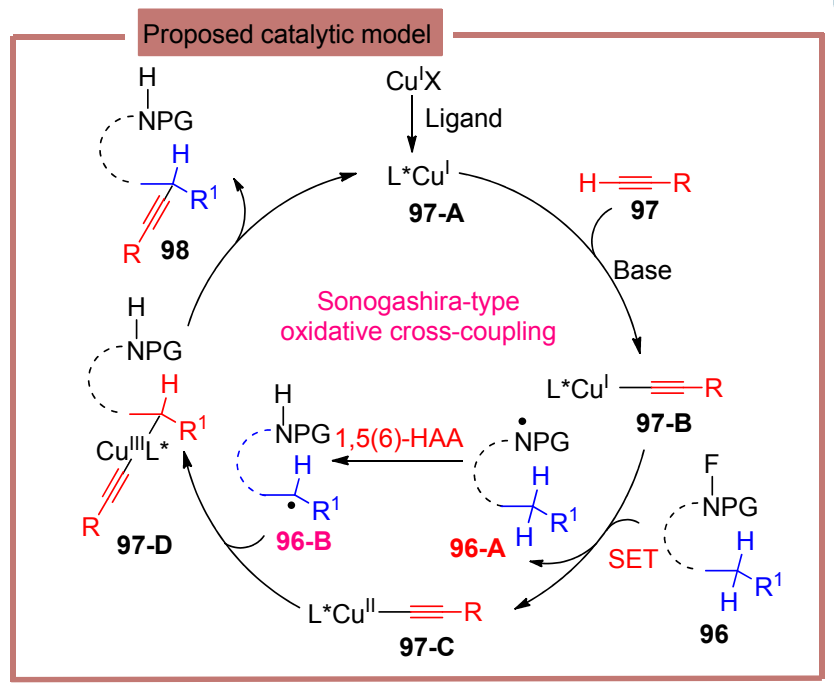

图式 40 铜催化不对称类 Sonogashira-类型氧化偶联反应

Scheme 40 Asymmetric Sonogashira-type oxidative cross-coupling catalyzed by copper

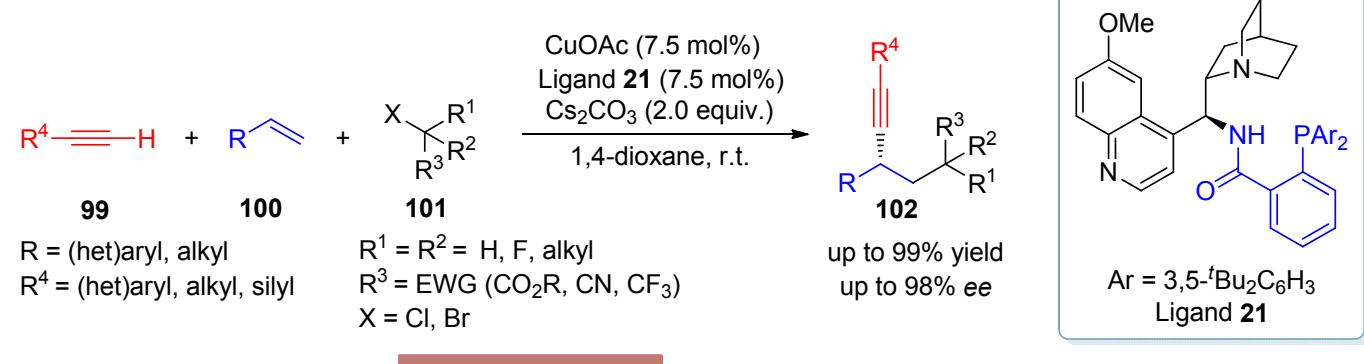

Proposed mechanism

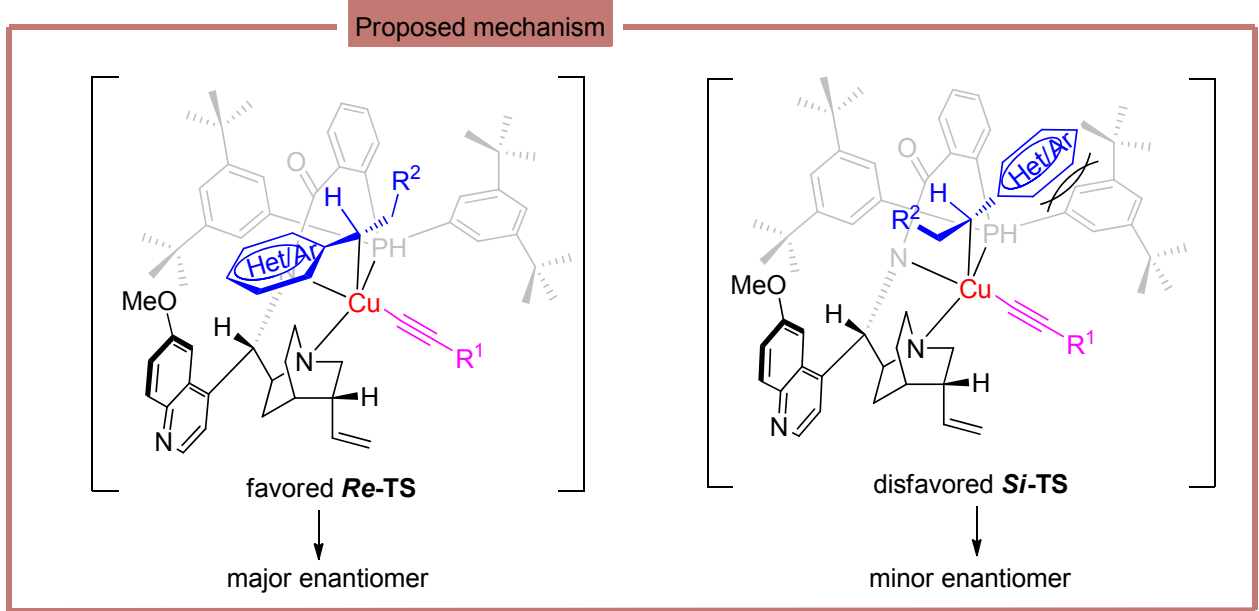

图式 41 铜催化烯烃的不对称自由基 1,2-碳炔基化反应

Scheme 41 Copper-catalyzed asymmetric radical 1,2-carboalkynylation of alkenes

\section{References}

[1] Yang, F.; Hanon, S.; Lam, P.; Schweitzer, P. Am. J. Med. 2009, 122,
317.

[2] Haas, L. F. J. Neurol., Neurosurg. Psychiatry 1994, 57, 1333.

[3] Rabe, P.; Ackerman, E.; Schneider, W. Chem. Ber. 1907, 40, 3655. 
[4] Woodward, R. B.; Doering, W. E. J. Am. Chem. Soc. 1945, 67, 860.

[5] Carter, O. L.; McPhail, A. T.; Sim, G. A. J. Chem. Soc. A 1967, 365.

[6] Stork, G.; Niu, D.; Fujimoto, R. A.; Koft, E. R.; Balkovec, J. M.; Tata, J. R.; Dake, G. R. J. Am. Chem. Soc. 2001, 123, 3239.

[7] Yeboah, E. O.; Yeboah, S.; Singh, G. Tetrahedron 2011, 67, 1725.

[8] Boratyński, P. J.; Błajet, M. Z; Skarżewsk, J. Textbook of The Alkaloids: Chemistry and Biology, Elsevier, Poland, 2019, p. 29.

[9] List, B. Angew. Chem., Int. Ed. 2010, 49, 1730.

[10] MacMillan, D. W. C. Nature 2008, 455, 304.

[11] (a) Kacprzak, K.; Gawronski, J. Synthesis 2001, 961

(b) Tian, S. K.; Chen, Y.; Hang, J.; Tang, L.; McDaid, P.; Deng, L. Acc. Chem. Res. 2004, 37, 621.

(c) Singh, G.; Yeboah, E. Rep. Org. Chem. 2016, 6, 47.

[12] Shi, L. M.; Dong, W. W.; Tao, H. Y.; Dong, X. Q.; Wang, C. J. Org. Lett. 2017, 19, 4532.

[13] Shao, Y. D.; He, X. Y.; Han, D. D.; Yang, X. R.; Yao, H. B.; Cheng, D. J. Asian J. Org. Chem. 2019, 8, 2023.

[14] Mukhopadhyay, S.; Pan, S. C. Eur. J. Org. Chem. 2019, 2639.

[15] Nakamura, S.; Hayama, D.; Miura, M.; Hatanaka, T.; Funahashi, Y. Org. Lett. 2018, 20, 856.

[16] Takata, S.; Endo, Y.; Ullah, M. S.; Itsuno, S. RSC Adv. 2016, 6, 72300 .

[17] Endo, Y.; Takata, S.; Kumpuga, B. T.; Itsuno, S. ChemistrySelect 2017, 2, 10107.

[18] Reddy, R. R.; Gudup, S. S.; Ghora, P. Angew. Chem. Int. Ed. 2016, 55,15115 .

[19] Mondal, K.; Pan, S. C. J. Org. Chem. 2018, 83, 5301.

[20] Wu, Y. C.; Jhong, Y.; Lin, H. J.; Swain, S. P.; Tsaia, H. H. G.; Hou, D. R. Adv. Synth. Catal. 2019, 361, 4966.

[21] Jiang, H. Y.; Li, Q.; Qi, Q. J.; Yang, C. X.; Zhang, D. Chin. J. Org. Chem. 2018, 38, 825 (in Chinese). (姜海洋, 李强, 齐庆杰, 杨晨曦, 张丹, 有机化学, 2018, 38, 825.)

[22] Zhu, W.-R.; Liu, K.; Huang, W.-H.; Huang, W.-J.; Chen, Q.; Weng, J.; Lin, N.; Lu, G. Org. Lett. 2020, 22, 5014.

[23] Zi, Y.; Lange, M.; Schultz, C.; Vilotijevic, I. Angew. Chem. Int. Ed. 2019, 58, 10727.

[24] Breman, A. C.; Heijden, G. V. D.; Maarseveen, J. H. V.; Ingemann, S.; Hiemstra, H. Chem. Eur. J. 2016, 22, 14247.

[25] Kumpuga, B. T.; Itsuno, S. Asian J. Org. Chem. 2019, 8, 251.

[26] Tichá, I. C.; Hybelbauerová, S.; Jindřich, J. J. Org. Chem. 2019, 15, 830 .

[27] Kolb, H. C.; VanNieuwenhze, M. S.; Sharpless, K. B. Chem. Rev. 1994, 94, 2483.

[28] Yang, F.; Zhao, D. B.; Lan, J. B.; Xi, P. H.; Yang, L.; Xiang, S. H.; You, J. S. Angew. Chem. Int. Ed. 2008, 47, 5646.

[29] Wang, J.; Wang, W. T.; Li, W.; Hu, X. L.; Shen, K.; Tan, C,; Liu, X. H.; Feng, X. M. Chem. Eur. J. 2009, 15, 11642.

[30] Su, Z. S.; Li, W. Y.; Wang, J.; Hu, C. W.; Feng, X. M. Chem. Eur. J. 2013, 19, 1637.

[31] Wang, W. T.; Shen, K.; Hu, X. L.; Wang, J.; Liu, X. H.; Feng, X. M. Synlett 2009, 1655.

[32] Wang, J.; Li, W.; Liu, Y. L.; Chu, Y. Y.; Lin, L. L.; Liu, X. H.; Feng, X. M. Org. Lett. 2010, 12, 1280.
[33] Shi, J.; Wang, M.; He, L.; Zheng, K.; Liu, X. H.; Lin, L. L.; Feng, X. M. Chem. Commun. 2009, 31, 4711.

[34] Richter, C.; Ranganath, K. V. S.; Glorius, F. Adv. Synth. Catal. 2012, 354, 377.

[35] Hartikka, A.; Modin, S. A.; Arvidsson, P. G. Org. Biomol. Chem. 2003, $1,2522$.

[36] He, W.; Liu, P.; Zhang, B. L.; Sun, X. L.; Zhang, S. Y. Appl. Organomet. Chem. 2006, 20, 328.

[37] Hayashi, M.; Shiomi, N.; Funahashi, Y.; Nakamura, S. J. Am. Chem. Soc. 2012, 134, 19366.

[38] Hayashi, M.; Iwanaga, M.; Shiomi, N.; Nakane, D.; Masuda, H.; Nakamura, S. Angew. Chem. Int. Ed. 2014, 53, 8411.

[39] Yamaji, R.; Iwanaga, M.; Nakamura, S. Chem. Commun. 2016, 52, 7462.

[40] Shen, B.; Huang, H. Y.; Bian, G. L.; Zong, H.; Song, L. Chirality 2013, 25, 561 .

[41] Liu, M.; Ma, S. J.; Tian, Z. Q.; Wu, H.; Wu, L. L.; Xu, X. F.; Huang, Y. D.; Wang, Y. M. Tetrahedron: Asymmetry 2013, 24, 736.

[42] Li, X. T.; Gu, Q. S.; Dong, X. Y.; Meng, X.; Liu, X. Y. Angew. Chem. Int. Ed. 2018, 57, 7668 .

[43] Li, X. T.; Lv, L.; Wang, T.; Zhang, X. H.; Cheng, G. J.; Liu, X. Y. Chem 2020, 6, 1692.

[44] Tian, Q. Q.; Liu, Y. L.; Wang, X. Y.; Wang, X.; He, W. Eur. J. Org. Chem. 2019, 24, 3850.

[45] Zielińska, B. M.; Skarżewski, J. Tetrahedron: Asymmetry 2009, 20, 1992.

[46] Wei, Y.; Yao, L.; Zhang, B. L.; He, W.; Zhang, S. Y. Tetrahedron 2011, 67, 8552 .

[47] Wang, Q. F.; He, W.; Liu, X. Y.; Chen, H.; Qin, X. Y.; Zhang, S. Y. Tetrahedron: Asymmetry 2008, 19, 2447.

[48] Sladojevich, F.; Trabocchi, A.; Guarna, A.; Dixon, D. J. J. Am. Chem. Soc. 2011, 133, 1710.

[49] Campa, R.; Dixon, D. J. Angew. Chem. Int. Ed. 2015, 54, 4895.

[50] Ortin, I.; Dixon, D. J. Angew. Chem. Int. Ed. 2014, 53, 3462.

[51] Campa, R.; Yamagata, A. D. G.; Ortin, I, Franchino, A.; Thompson, A. L.; Odell, B.; Dixon, D. J. Chem. Commun. 2016, 52, 10632.

[52] Manzano, R.; Rubén; Datta, S.; Paton, R.; Dixon, D. J. Angew. Chem. Int. Ed. 2017, 56, 5834.

[53] Zheng, S. C.; Wang, Q.; Zhu, J. P. Angew. Chem. Int. Ed. 2019, 58 , 1494.

[54] Casarotto, V.; Li, Z. T.; Boucau, J.; Lin, Y. M. Tetrahedron. Lett. 2007, 48, 5561.

[55] Yao, L.; Wei, Y.; Wang, P. G.; He, W.; Zhang, S. Y. Tetrahedron 2012, 68, 9119.

[56] Dong, X. Y.; Zhang, Y. F.; Ma, C. L; Gu, Q. S.; Wang, F. L.; Li, Z. L.; Jiang, S. P.; Liu, X. Y. Nat. Chem. 2019, 11, 1158.

[57] Xia, H. D.; Li, Z. L.; Gu, Q. S.; Dong, X. Y.; Fang, J. H.; Du, X. Y.; Wang, L. L.; Liu, X. Y. Angew. Chem. Int. Ed. 2020, 59, 16926.

[58] Zhang, Z. H.; Dong, X. Y.; Du, X. Y.; Gu, Q. S.; Li, Z. L.; Liu, X. Y. Nat. Commun. 2019, 10, 5689.

[59] Dong, X.-Y.; Cheng, J.-T.; Zhang, Y.-F.; Li, Z.-L.; Zhan, T.-Y.; Chen, J.-J.; Wang, F.-L.; Yang, N.-Y.; Ye, L.; Gu, Q.-S.; Liu, X.-Y. J. Am. Chem. Soc. 2020, 142, 9501 . 